\title{
Signaling pathways in a Citrus EST database
}

\author{
Angela Mehta ${ }^{1}$, Marilia Santos Silva ${ }^{2}$, Simone Guidetti-Gonzalez ${ }^{3}$, Helaine Carrer $^{3}$, \\ Marco Aurélio Takita ${ }^{4,5}$ and Natália F. Martins ${ }^{1}$ \\ ${ }^{1}$ Embrapa Recursos Genéticos e Biotecnologia, Brasília, DF, Brazil. \\ ${ }^{2}$ Embrapa Cerrados, Planaltina, DF, Brazil. \\ ${ }^{3}$ Departamento de Ciências Biológicas, Escola Superior de Agricultura Luiz de Queiroz, \\ Universidade de São Paulo, SãoPaulo, SP, Brazil. \\ ${ }^{4}$ Centro APTA Citros Silvio Moreira, Instituto Agronômico de Campinas, Cordeirópolis, SP, Brazil. \\ ${ }^{5}$ Centro de Pesquisa e Desenvolvimento de Recursos Genéticos Vegetais, \\ Instituto Agronômico de Campinas, Campinas, SP, Brazil.
}

\begin{abstract}
Citrus spp. are economically important crops, which in Brazil are grown mainly in the State of São Paulo. Citrus cultures are attacked by several pathogens, causing severe yield losses. In order to better understand this culture, the Millenium Project (IAC Cordeirópolis) was launched in order to sequence Citrus ESTs (expressed sequence tags) from different tissues, including leaf, bark, fruit, root and flower. Plants were submitted to biotic and abiotic stresses and investigated under different development stages (adult vs. juvenile). Several cDNA libraries were constructed and the sequences obtained formed the Citrus ESTs database with almost 200,000 sequences. Searches were performed in the Citrus database to investigate the presence of different signaling pathway components. Several of the genes involved in the signaling of sugar, calcium, cytokinin, plant hormones, inositol phosphate, MAPKinase and COP9 were found in the citrus genome and are discussed in this paper. The results obtained may indicate that similar mechanisms described in other plants, such as Arabidopsis, occur in citrus. Further experimental studies must be conducted in order to understand the different signaling pathways present.
\end{abstract}

Key words: Citrus, cell signaling, genomics.

Received: July 21, 2006; Accepted: June 8, 2007.

\section{Introduction}

Cell-cell and cell-environment communication (signal transduction) is crucial for the development of multicellular organisms. In plants, cell signaling connects the environmental input to the intracellular responses in plants. Cold, drought, and salt stresses all stimulate the accumulation of compatible osmolytes and antioxidants. Given the multiplicity of signals in a plant lifetime, there is a wide range of external and internal signals leading to cell response. Exogenous and endogenous signals play an important role in cell metabolism leading to growth and defense responses (Xiong et al., 2002). Recent advances in plant signaling research revealed that plants respond to signals activating the cell signaling network that comprises calcium sensors and signaling, sugar signaling, plant hormone

Send correspondence to Natalia F. Martins. Laboratório de Bioinformática, Embrapa - Recursos Genéticos e Biotecnologia, Parque Estação Biológica, Av. W5 Norte (final), Caixa Postal 02372, 70770-900 Brasília, DF, Brazil. E-mail: natalia@cenargen. embrapa.br. response (ABA, JA), cytokinins, phosphorylation cascade and peptides which have well characterized roles in the multicellular coordination of plant physiology, development, defense and other processes. But little is known still about plant cell signaling, although the Arabidopsis and plant genomics allowed the identification of many signaling pathways (Button et al., 2006).

The identification of all signaling components and messengers that mediate transduction pathways and the analysis of their function and regulation and cross talk among these components should help in understanding the inner workings of plant cell responses to diverse signals. Knowledge about cell signaling is also important for the continued development of rational breeding and genetic modification strategies to improve tolerance in crops. In the present work we attempt to present the citrus components and signaling pathways network grouped into different categories. We also indicate some possible features for the cross talk in citrus development and physiological processes. 


\section{Calcium signaling pathway}

$\mathrm{Ca}^{2+}$ is an important cell messenger with fundamental roles in signal transduction networks of all eukaryotes. In plants, $\mathrm{Ca}^{2+-}$ dependent protein kinase (CDPK) activities are related to growth, reproduction and development, including responses to drought, cold and salt stresses, mechanical wounding and pathogens. Moreover, the $\mathrm{Ca}^{2+}$ signals are implicated in responses to hormones such as ABA, giberellic acid, cytokinin and others.

The transient increases in cytosolic $\mathrm{Ca}^{2+}$ and ion influx through calcium channels are perceived by CDPKs and the SOS3 family (Xiong et al., 2002). CDPKs (calcium-dependent protein kinases or calmodulin-like domain protein kinases) are activated by the binding of calcium to their calmodulin-like regulatory domains. The CDPKs superfamily consists of serine/threonine protein kinases with a C-terminal calmodulin-like domain with up to 4 EF-hand motifs that directly bind to $\mathrm{Ca}^{2+}$. The carboxyl terminal domains of CRKs (CDPK-related kinases) have sequence similarity to the regulatory domains of CDPKs, but do not bind calcium. PPCKs (PEP carboxylase kinases) contain only one catalytic domain. PRKs (PPCK-related kinases) have a carboxyl-terminal domain that has no similarity to that of any other member of the superfamily. CCaMKs (calcium and calmodulin regulated kinases) bind both calcium ions and the calcium/calmodulin complex, whereas CaMKs (calmodulin-dependent protein kinases) bind the calcium/ calmodulin complex, but not calcium.

The structural similarity among CDPKs (also called CPKs) allowed their classification into three groups: CDPK, CCaML and CRK. Their unique structure is defined by a kinase catalytic domain in the C-terminal fused to a regulatory calmodulin-like domain (CaM-LD). Two models are in use representing the calcium activation mechanism (Harper et al., 2004). In the first model, CDPKs represent sensor responders in which a flexible tether joins the kinase CaM-LD domain covalently. Upon calcium stimulation, this domain replaces the autoinhibitor segment and starts the signaling cascade. The second model proposes that the regulation by CRKs, CCaMKs and SnRK3 occurs through an exogenous $\mathrm{Ca}^{2+}$ binding that relays the conformational change to the kinase domain as a consequence of calcium binding.

\section{Cytokinin signaling pathway}

Cytokinins are important regulators of a large number of processes in plant development. The plasticity and adaptation allow plants to respond sensitively and quickly to their environmental stimuli. Recent studies have demonstrated that cytokinin signaling involves a multistep twocomponent signaling pathway through a common model of cytokinin signaling that is likely representative in plants. Each system consists of a sensor protein histidine kinase, which is anchored in the cell membrane, and a cytoplasmic response regulator, whose activity is modulated by the sensor (Harper et al., 2004).

The histidine kinases are named CKI1 (from cytokinin-independent 1 two-component response regulator), AHK2 (from Arabidopsis thaliana histidine kinase 2), AHK3 and CRE1 (from cytokinin receptor). CytokininIndependent 1 (CKI1) belongs to a group of putative plant histidine kinases whose members do not appear to act as ethylene receptors (Pischke et al., 2006). The regulators are named AHPs (from 1 to 5, Arabidopsis thaliana histidine phototransmitter) and ARRs classified in A-type and Btype Arabidopsis thaliana response regulators (Oka et al., 2002).

The cytokinin signal is perceived by histidine protein kinases at the plasma membrane: CKI1, AHK2, AHK3 or CRE1. Following the cytokinin signal, these histidine protein kinases initiate a signaling cascade through the phosphorelay that results in the nuclear translocation of AHPs from the cytosol. Activated AHPs interact with sequestered ARRs or ARR complexes in the nucleus, transfer the phosphate to the receiver domain of their cognate B-type ARRs, and in turn release the transcription activator ARRs from putative repressors in the nucleus. The dephosphorylated AHP shuttles back to the cytosol, where it can be rephosphorylated. The liberated ARRs bind to multiple cis elements in the promoters of target genes. The activation of the transcription repressor ARRs as cytokinin primary response genes provides a negative feedback mechanism (Oka et al., 2002).

\section{Ethylene signaling pathway}

Ethylene is a plant hormone involved in several processes including flower and leaf senescence, fruit ripening and biotic/abiotic stress responses such as drought, chilling, flooding, wounding and pathogen infection. The main signaling components of the ethylene transduction pathway include (i) an ethylene receptor (ETR) to sense the hormone; (ii) the downstream constitutive triple response 1 (CTR1) Raf-like serine/threonine kinase; followed by (iii) the ethylene insensitive-2 (EIN2) positive regulator of the pathway; then (iv) the family of ethylene insensitive-3 (EIN3) transcription factors which regulate the expression of (v) the family of ethylene response element biding protein (EREBP) transcription factors (Guo and Ecker, 2004). The addition of ethylene inactivates the ethylene receptors (negative regulation of downstream responses), which in turn no longer activates CTR1, resulting in the release of suppression of EIN2 and consequential activation of EIN3. The EIN3 transcription factor binds to regulatory sequences in the promoter of ethylene-regulated genes initiating a transcriptional cascade that culminates in ethylene response.

Several EREBP transcription factors are known to be immediate targets of the EIN3 transcription factors. The EREBP factor named ethylene response factor 1 (ERF1) is 
involved in both ethylene and jasmonate signaling, representing a cross-talk point between the two signal transduction pathways (Lorenzo et al., 2003). Other EREBP factors regulate gene expression via association with the cis-element GCC-box present in several ethylene-responsive genes involved, for instance, in resistance to pathogens and differential cell growth.

The ethylene signal transduction pathway seems to be conserved among agronomically important dicot and monocot plants, though some particularities may be observed (Klee, 2004).

\section{ABA signaling pathway}

ABA (abscisic acid) is an important hormone associated to late seed development and adaptation to environmental stresses. A simple ABA signaling pathway has not been defined yet; however, some ABA insensitive genes have been identified, such as ABI1 and ABI2, which are involved in vegetative and seed $\mathrm{ABA}$ responsiveness. ABI1 and $\mathrm{ABI} 2$ genes encode homologous type $2 \mathrm{C}$ protein phosphatases and $\mathrm{ABI}, \mathrm{ABI} 4$ and $\mathrm{ABI} 5$ genes encode transcription factors of the $\mathrm{B} 3$ domain, APETALA2 (P2) domain and bZIP factor classes, respectively. Pei et al. (1998) have identified farnesyl transferase (ERA1) as an attenuator of seed and vegetative ABA sensitivity in mutants with enhanced response to $\mathrm{ABA}$. It has been reported that $\mathrm{ABI} 1 / 2$ acts at or above ERA 1 and both of these genes act at or above ABI3 and ABI5 (Pei et al., 1998).

In Arabidopsis thaliana, several different genes have been associated with the ABA response including PGGT-I (Johnson et al., 2005), the gene encoding the b-subunit of protein geranylgeranyltransferase type I (PGGT I). Cross-talk between ABA and Inositol 1,4,5-triphosphate dephosphorylation is also important in this signal transduction since mutation in fry 1 , the inositol polyphosphate 1-phosphatase encoding gene, leads to super-induction of ABA- and stress-responsive genes (Xiong et al., 2002). Other genes involved in the ABA response participate in the RNA metabolism like hyl1 (Lu et al., 2002), a gene encoding a double-stranded RNA binding protein that is related to activity of MAP kinases (Lu et al., 2002); abh1 (Hugouvieux et al., 2001), a gene encoding an mRNA cap binding protein that modulates the ABA signaling by affecting transcription of early ABA signaling elements; and sad1, that encodes a polypeptide similar to multifunctional Sm-like snRNP proteins required for mRNA splicing, export and degradation (Xiong et al., 2001). Other non-transcription factor-encoding genes are also involved in the ABA response such as genes encoding NADPH oxidase, rboHD and $\mathrm{F}$ (Kwak et al., 2003), showing that reactive oxygen species are second messengers in ABA signaling.

\section{Sugar signaling pathways}

Soluble sugars, such as glucose and sucrose, seem to regulate diverse plant developmental, physiological and metabolic processes through several pathways (Rolland et al., 2002). Rolland et al., (2002) have proposed a model for possible sugar signals and sensing sites. According to these authors, sugar such as glucose (Glc) and fructose (Fru) can be transported into the cell by hexose transporters. After hexokinase (HXK) catalyzed phosphorylation, Glc enters the metabolism. The HXK sugar sensor (a protein in the cytosol or in association with an organelle) could activate a signaling pathway through HXK interacting proteins or affect transcription directly after nuclear translocation. Rolland et al. (2002) also suggest that different HXK and fructokinase (FRK) isoforms and HXK-like proteins have distinct metabolic and signaling functions. Metabolic intermediates could trigger signal transduction by activating metabolite sensors. These authors propose that SnRK protein kinases might act as sensors of metabolic activity. SnRKs play an important role in carbon metabolism by directly phosphorylating and inactivating the biosynthetic key enzymes 3-hydroxy-3-methyl glutaryl CoA reductase, nitrate reductase (NR) and Suc phosphate synthase (Sugden et al., 1999).

The yeast SNF1 Ser/Thr PK is well characterized and is one of the major components in sugar signaling. It has been demonstrated that low glucose concentrations activate SNF1 kinase, which result in the phosphorylation of the transcriptional repressor Mig1, causing its translocation to the cytoplasm and derepression of target genes (Alberti et al., 2003). SNF1 can also directly affect the transcription machinery through the interaction with the Srb/mediator complex of RNA polymerase II and histone phosphorylation (Lo et al., 2001). Molecular analyses have revealed the existence of a large family of SnRKs in plants and several SnRKs have been shown to complement the yeast snf1? phenotype (Hrabak et al., 2003). The SNF1 kinase is a conserved complex and the subunits SNF4, SIP homologue and SnRK, also called SNF1-related kinase, have been reported in plants (Smeekens, 2000).

\section{Jasmonic acid signaling pathway}

Jasmonates (JAs) are signaling molecules that orchestrate plant responses to biotic and abiotic stresses locally and systemically. The term jasmonate includes the active intermediates in the jasmonic acid biosynthesis as well as the derivatives of jasmonic acid. JAs are widely distributed in plants and affect several processes such as fruit ripening, pollen maturation, root growth and defenses against insects and pathogens. It has been proposed that wounding causes release of linolenic acid, which is a precursor for JA, and that an E3 ubiquitin ligase probably regulates most JA responses in Arabidopsis (Turner et al., 2002). JA signaling is best known in Arabidopsis and tomato; however, there are discrepancies in the proposed pathways and it is not clear if these divergences are due to differences in the mechanisms or lack of knowledge. 
Two mechanisms by which JAs activate gene expression have been reported. The best characterized pathway involves components including coronatine insensitive 1 (COI1) and jasmonic acid resistant1 (JAR1) (Staswick et al., 2002). Cyclopentenones, such as oxo-phytodienoic acid (OPDA) and the cyclopentanone JA participate in this signal transduction pathway. These compounds activate and repress the expression of several genes. The second mechanism involves only the cyclopentenone jasmonates, such as OPDA, which can alter gene expression (Farmer $e t$ al., 2003).

Two multiprotein complexes have been reported to play a central role in jasmonate signaling; one is the COP9 signalosome (CNS), further discussed in this paper, and the other is the SCFCOI1 complex. The defining feature of the SCFCOI1 complex is COI1, which can associate physically with Skp-like proteins, cullin and Arabidopsis thaliana RING-box1 (AtRbx1) to form active SCFCOI1 complexes that function as E3-type ubiquitin ligases (Xu et al., 2002). Once activated by jasmonates, SCFCOI1 targets regulatory proteins for ubiquitination by modifying their activity or by targeting their proteolysis. Histone deacetylase can interact with COI1 and is a newly identified candidate regulator of jasmonate responses (Devoto et al., 2002). Orca3, an apetala2 (AP2)/ethylene-responsive factor (ERF)-domain transcription factor is one of the regulatory proteins found downstream in the jasmonate signaling pathway (Memelink et al., 2001).

\section{COP9}

The COP9 signalosome (CSN) was first identified as an important photomorphogenesis actor in plants. Biochemical studies in both plants and animals have demonstrated that CSN is a conserved nuclear protein complex with eight subunits highly homologous to the lid sub-complex of $26 \mathrm{~S}$ proteasome that participates in several cellular processes, ranging from transcriptional regulation to protein degradation. Protein kinases called CSN-associated kinases are involved in these cellular responses.

CSN activities mainly include the following: an associated kinase that phosphorylates $\mathrm{p} 53$, c-Jun and other regulatory proteins; deneddylation of the Cullin-1 subunit of the SCF E3 ubiquitin ligase complex; mediation of the nuclear export of $\mathrm{p} 27 \mathrm{kip} 1$; and mediation of the nuclear import of COP1. One of the major targets is the SCF ubiquitin ligase complex that catalyzes a key step in ubiquitinilation. Also, it has been pointed out that the neddilation pathway is a target of CSN suggesting that this role has a significant influence over auxin response. However, the mechanisms and interconnections of COP9 functions are still not clearly understood (Wei and Deng, 2003).

\section{Kinases and phosphatases}

Phosphorylation and dephosphorylation are catalyzed by kinases and phosphatases, respectively, and many signal transduction processes depend on the reversible phosphorylation of proteins.

MAPKs (mitogen-activated protein kinases) are serine/threonine protein kinases that play key roles in integrating multiple intracellular signals transmitted by various second messengers. All eukaryotes utilize MAPK cascades to convey signals that are generated from the perception of both extra- and intracellular stimuli. MAPK cascades are multicomponent pathways that consist of at least three protein kinases, mediating sequential phosphorylation reactions. A MAPK kinase kinase (MAPKKK) phosphorylates and activates a MAPK kinase (MAPKK), which, in turn, activates a MAPK by phosphorylation (Chen and Cobb, 2001). The cascades of the MAPKs are involved in ethylene signal transduction, JA biosynthesis pathway, phytoalexin biosynthesis in parsley cell cultures, defense responses and hypersensitive cell death (Ligterink and Hirt, 2001).

Glycogen synthase kinases (GSK) are a family of cytoplasmic kinases that belong to the mitogen-activated protein kinase superfamily and are found in animals, fungi, and plants (Tavares et al., 2002). There is evidence that two Arabidopsis GSK3 are involved in floral development (Dornelas et al., 2000) and one plays a crucial role in brassinosteroids signaling and in alfalfa GSK3 is involved in wound signaling (Jonak and Hirt, 2002).

Casein kinases are critical in cell division and differentiation across species. Liu et al. (2003) suggested that casein kinase 1 (Ck1) from rice might be involved in the root development signaling pathways that are regulated by abscisic acid and brassinosteroid hormones. On the other hand, casein kinase $2(\mathrm{Ck} 2)$ is one of the most pleiotropic protein kinases with hundreds of protein substrates involved in a variety of cellular functions with special reference to signaling, nuclear organization, and gene expression (Boldyreff et al., 1993).

Protein Ser/Thr phosphatases are divided into the protein phosphatase $\mathrm{P}$ (PPP) and protein phosphatase M (PPM) families, which have distinct amino acid sequences and crystal structures (Kutuzov and Andreeva, 2002). The PPM family mainly consists of PP2C phosphatases and the PPP family contains protein phosphatases 1 (PP1), 2A (PP2A), 2B (PP2B), 5 (PP5) and RdgC/protein phosphatase 7 (PP7) (Kerk et al., 2002). In plants, one of the roles of PP2Cs is involved in the regulation of MAPK pathways (Meskiene et al., 1998) and two PP2C from Arabidopsis (ABI1 and $\mathrm{ABI}$ ) act as negative regulators of ABA signaling (Merlot and Firtel, 2003).

Kinase-associated protein phosphatase (KAPP) interacts with many other plant receptor kinases. For example, KAPP is phosphorylated by CLV1 (CLAVATA1) and dephosphorylates the kinase domain of this receptor in vitro (Stone et al., 1998).

Tyrosine-specific protein phosphatase have roles in processes as diverse as pollen development (Gupta et al., 
2002), stomatal opening, and regulate the mitogen-activated protein kinases (MAPKs) involved in a variety of signaling pathways.

\section{Inositol phosphate}

Inositol metabolism is essential for the development of plants, animals, and some microorganisms. Inositol is a sugar that plays essential roles in many cellular processes including membrane formation, cell wall biogenesis, stress response as well as signal transduction. It has been implicated in stress tolerance and possibly also in carbohydrate transport (Liu et al., 2006). Inositol phosphates are essential to signaling in almost all organisms and in plants, inositol hexaphosphate provides for phosphate storage (Perera et al., 2006).

\section{Signaling peptides}

Plant peptides are important in various signaling pathways and have been identified in several plants (for a review see Ryan et al., 2002). The plant peptide systemin was discovered during a search for the systemic wound signal that regulates the expression of defensive genes in tomato leaves in response to insect attacks or other severe mechanical wounding (Chilley, 2003). Systemin is recognized by the SR160 receptor-like kinase, which induces defense gene activation. The plant peptide phytosulfokine (PSK) interacts with the receptor-like kinase PSKR and activates a set of genes responsible for cellular dedifferentiation and redifferentiation. Clavata3 is translated, secreted and binds a Clavata1/Clavata2 receptor-like kinase complex, which regulates the balance between meristem cell proliferation and differentiation (Rojo et al., 2002).

\section{Materials and Methods}

Citrus ESTs (expressed sequence tags) have been sequenced by the Millenium Project (IAC Cordeirópolis). Different tissues (leaf, bark, fruit, root and flower) from Citrus spp. and Poncirus trifolia were submitted to biotic and abiotic stresses and investigated at different development stages (adult $v s$. juvenile). Several cDNA libraries were constructed and the sequences obtained formed the Citrus ESTs (CitEST) database with almost 200,000 sequences.

To investigate signaling pathway components in the database (http://citest.centrodecitricultura.br), we used two strategies: the first one was a key word search and the second was a BLASTn or tBLASTn (Altschul et al., 1997) search using well annotated queries retrieved in Genbank (www.ncbi.nlm.nih.gov). The parameters used for the reverse annotation were an e-value filter of e-4 and no low complexity filtering. Once selected, the reads were submitted to clustering by using the program CAP3 and the assembly results were organized by project/gene name or subject (Huang and Madan, 1999). Manual annotation confirmed ortholog similarity.

\section{Results and Discussion}

\section{Calcium signaling pathway in Citrus}

$\mathrm{Ca}^{2+}$ signals play an important role in many aspects of plant growth and development, including the response to biotic and abiotic stresses. One of the most intriguing aspects of $\mathrm{Ca}^{2+}$ signaling in plants is the occurrence of a large family of related isoforms, in contrast to a more specific situation in animals where, for example CaM isoform is encoded by three genes.

Advances over the last decade in genomics have made it possible to identify gene expression as well as orthologs by in silico search. The comparative approach for sequence similarities showed the overall patterns of gene network systems at the amino acid level. Bioinformatics in the CitEST database indicated a great number of contigs and singlets related to calcium signaling proteins (Table 1). The most abundant form of a calcium sensor found was CDPK1 including the forms CDPK2, CDPK3, CDPK6, CDPK 7, CDPK9, CDPK19, and CDPK-like. For CRK and CaMK3 only one singlet was found for each gene, indicating that further investigation is needed. In contrast, the SNRK1 gene seemed to be highly expressed in the Citrus transcriptome in which several ESTs corresponding to isoforms of SNRK1 were identified (CIPK1, CIPK8, CIPK9, CIPK12 and CIPK25). The calcinerin family was identified through several isoforms, including CBL10 (the most abundantly expressed), CBL3, CBL1 and a calcinerin-like ortholog. The main calcium signaling components found in the Citest database are shown in Figure 1A.

Our results are in agreement with other finding in plants. In Arabidopsis, 67 CDPKs implicated in $\mathrm{Ca}^{2+}$ signaling have been found (Harper et al., 2004). Among this group, 34 were identified as CDPKs, 8 genes of CRK, 38 SNRKs and the largest family identified was SnRK3. In the Citrus EST database, the largest family was CDPKs followed by SNRKs.

Although the families of kinase have been implicated in calcium signaling through different mechanisms, they all bind calcium sensors via EF-hands domains. Calcium concentration oscillation relays plant cell responses to environmental stresses through a complex interconnected network. Many abiotic stimuli induce a transient cytosolic calcium increase and consequently, the gene expression of calcium sensors as CaMs and CDPKs are often induced.

The remaining questions regarding the possible mechanisms by which $\mathrm{Ca}^{2+}$ regulates diverse biochemical and molecular processes and eventually physiological processes in response to diverse signals are beginning to be understood. Our study suggests some common features between Citrus and other plants such as Arabidopsis and rice. Further experimental approaches, through microarray experiments for example, shall contribute to answers to these questions. 
Table 1 - Ortholog genes of Calcium signaling pathways found in the Citrus EST database.

\begin{tabular}{|c|c|c|c|c|c|c|}
\hline \multirow[t]{2}{*}{ 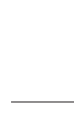 } & \multirow[t]{2}{*}{ Gene } & \multirow[t]{2}{*}{ Gene product } & \multirow[t]{2}{*}{ Organism } & \multirow[t]{2}{*}{ Accession \# } & \multicolumn{2}{|c|}{ Clusters } \\
\hline & & & & & Contigs & Singlets \\
\hline \multirow{21}{*}{ 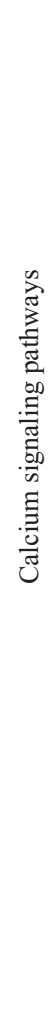 } & & CDPK & Arabidopsis thaliana & $\mathrm{gb|AAT} 06478.1$ & 4 & 7 \\
\hline & & CDPK1 & Cicer arietinum & $\mathrm{gb} \mid \mathrm{AAP} 72281.2$ & 3 & 2 \\
\hline & & CDPK2 & Cicer arietinum & $\mathrm{gb} \mid \mathrm{AAP} 72282.2$ & 9 & 0 \\
\hline & & CDPK3 & Oryza sativa & $\mathrm{gb} \mid \mathrm{AAN} 41657.1$ & 2 & 0 \\
\hline & $C D P K^{I}$ & CDPK6 & Triticum aestivum & gi| 47522360 & 0 & 1 \\
\hline & & CDPK7 & Fragaria $x$ ananassa & AAB88537.1 & 0 & 4 \\
\hline & & CDPK9 & Nicotiana tabacum & gi|3283996 & 0 & 2 \\
\hline & & CDPK19 & Arabidopsis thaliana & NP_850853.1 & 1 & 0 \\
\hline & & CDPK-like & Solanum tuberosum & $\mathrm{gb} \mid$ AAM29184.1 & 1 & 2 \\
\hline & $C R K^{2}$ & CRK & Arabidopsis thaliana & gi|15226426 & 0 & 1 \\
\hline & $\mathrm{CaMK}^{3}$ & CaMK3 & Arabidopsis thaliana & $\mathrm{gb} \mid \mathrm{AAD} 12016.1$ & 2 & 0 \\
\hline & \multirow{6}{*}{$\operatorname{SnR} K^{4}$} & SNRK1 & $\begin{array}{l}\text { Cucumis sativus } \\
\text { Nicotiana tabacum }\end{array}$ & $\begin{array}{l}\text { CAA71142.1 } \\
\text { gi| } 496385\end{array}$ & 0 & 2 \\
\hline & & CIPK1 & Arabidopsis thaliana & $\mathrm{dbj} \mid \mathrm{BAB} 02040.1$ & 4 & 0 \\
\hline & & CIPK8 & Arabidopsis thaliana & gi|7446447 & 0 & 1 \\
\hline & & CIPK9 & Arabidopsis thaliana & $\mathrm{gb} \mid \mathrm{AAK} 26845.1$ & 1 & 1 \\
\hline & & CIPK12 & Arabidopsis thaliana & gi|7446437 & 0 & 1 \\
\hline & & CIPK25 & Arabidopsis thaliana & $\mathrm{gb} \mid$ AAL41008.1 & 1 & 0 \\
\hline & \multirow{4}{*}{$C B L^{5}$} & CBL10 & Arabidopsis thaliana & gb|AAO72364.1 & 2 & 0 \\
\hline & & CBL3 & Arabidopsis thaliana & gb|AAM91280.1 & 1 & 0 \\
\hline & & CBL1 & Arabidopsis thaliana & $\mathrm{dbj} \mid \mathrm{BAC} 43389.1$ & 1 & 0 \\
\hline & & Calcinerin-like & Eucalyptus grandis & AF197330_1 & 0 & 3 \\
\hline
\end{tabular}

\section{Cytokinin signaling pathway in Citrus}

A search for cytokinin members of the signaling pathway in the CitEST database indicated the pathways shown in Figure 1B. The most abundant members were AHK3, AHP5 and regulators ARR A and B-type. No full-length sequence was identified in the database and some genes such as CKI1 and CRE1 showed a weak similarity through Blastn search in CitEST.

Several contigs were related to AHK3 and ARR2 but few were assembled showing similarity to other members of the ARR family such as ARR6, ARR3, ARR11, ARR1 and ARR2 (Table 2). Considering these findings, one can suggest that the homologues of the three key proteins in a His/Asp phosphorelay are expressed in Citrus, as well as the response regulators. Those results are quite in agreement with the genes that have been identified in Arabidopsis and other eukaryotes such as yeasts (Pischke et al., 2006).

The Arabidopsis genome has revealed three cytokinin receptors (CRE1 and its homologues AHK2 and AHK3). Similar components are also found in maize, suggesting a conservation of the cytokinin signaling mechanism in plants (Kiba et al., 2005). The multistep two-component phosphorelay mechanism found in Arabidopsis is reminis- cent of the bacterial two-component signaling system (Suzuki et al., 2001).

In Citrus, we found evidence for the four major steps in the cytokinin signaling pathway: AHK sensing and signaling, AHP nuclear translocation, ARR transcription activation, and a negative feedback loop through cytokinininducible ARR gene products (Fig. 1B).

The importance of histidine protein kinase activity and phosphorelay has not been clearly demonstrated in plant cells yet. Nevertheless, conserved motifs for twocomponent phosphor-relay systems have been identified in ethylene receptors, phytochrome photoreceptors, and in a putative osmosensor (Pischke, 2006). The importance of multistep two-component phosphorelay has been investigated in Escherichia coli, yeasts and plants through transient expressions as well as in the leaf protoplast system. These studies have provided compelling evidence for a cytokinin role as a major sensing and propagating signal from a wide variety of external and/or internal stimuli such as ethylene, cytokinin, and osmolarity (Pischke, 2006).

\section{Ethylene signaling pathway in Citrus}

In Arabidopsis, there are five members of the ETR family, denoted as ETR1, ETR2, EIN4, ERS1 and ERS2, classified into two subfamilies: subfamily I (ETR1 and 
ERS1) and subfamily II (ETR2, EIN4 and ERS2) (Klee, 2004). In tomato, the predicted structures of the described ethylene receptors (LeETR1, LeETR2, NR, LeETR4, LeETR5 and LeETR6) are very similar to those in Arabidopsis (Klee, 2004). Within the CitEST database, we found several members of the ETR family (Table 3). A total of 63 unique reads related to ETR-like receptors were clusterized into 5 contigs and 2 singlets. The 5 contigs encode 3 receptors similar to subfamily I members (two ETR1 and one ERS1) and 2 receptors similar to subfamily II members (one EIN4 and one ETR5). These ETR-like contigs were representatively assembled from 7 up to 20

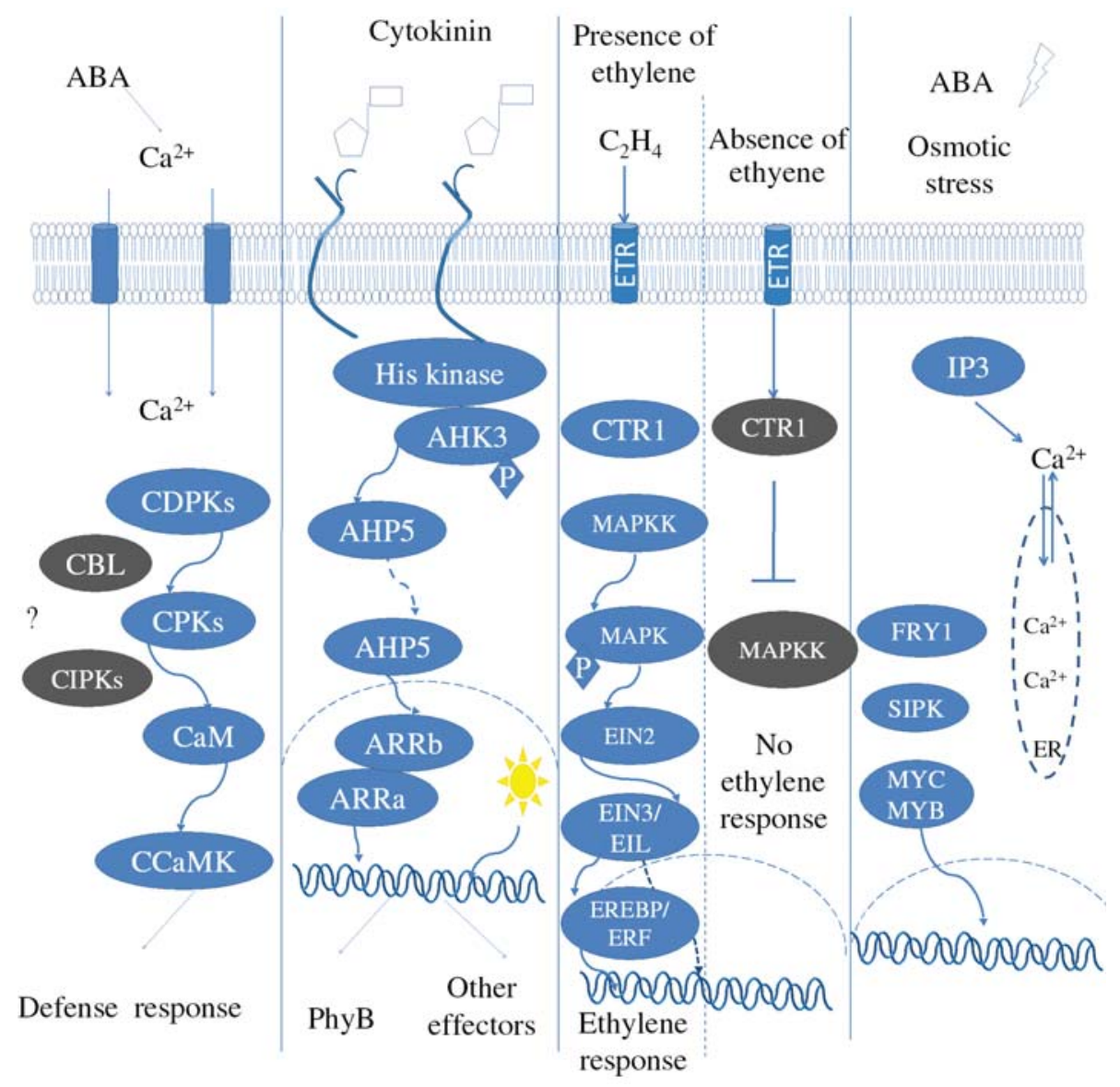

Figure 1 - Schematic representation of signaling cascades in Citrus. A. Calcium signaling components: CDPK (calcium-dependent protein kinase), CPK (calcium protein kinase), CaM (calmodulin), CCaMK (calcium- and calmodulin-dependent protein kinase), CBL (calcium sensor calcineurin B-like protein), CIPKs (CBL interacting protein kinases); B. cytokinin components: AHK3 (histidine kinase), AHP5 (Arabidopsis histidine phosphotransfer), $\mathrm{ARRa}$ and ARRb (Arabidopsis response regulator); C. Ethylene components: ETR (Ethylene receptor), CTR (Constitutive triple response), MAPKK (mitogen-activated protein kinase kinases), MAPK (mitogen-activated protein kinase), EIN (Ethylene insensitive), ERF (Ethylene response factor); D. Abscisic acid: IP3 (inositol triphosphate), FRY1(fiery1), SPK (sphingosine kinase), ER (Endoplasmatic Reticulum).

Table 2 - Ortholog genes of Cytokinin signaling pathways found in the Citrus EST database.

\begin{tabular}{lccccc}
\hline \multirow{2}{*}{ Gene } & Gene product & Organism & Accession $\#$ & \multicolumn{2}{c}{ Clusters } \\
\cline { 5 - 6 } & & & & Contigs & Singlets \\
\hline \multirow{2}{*}{ AHK3 } & AHK3 & Arabidopsis thaliana & At1g27320 & 2 & 2 \\
\hline AHP5 & AHP3 & Arabidopsis thaliana & At5g39340 & 1 & 1 \\
\hline \multirow{2}{*}{ ARR - A type } & ARR6 & Zea mays & BAB20581.1 & 1 & 1 \\
\hline \multirow{3}{*}{ ARR $-B$ type } & ARR3 & Dianthus caryophyllus & AAK14395.1 & 1 & 0 \\
\hline & ARR1 & Oryza sativa & BAD82798.1 & 1 & 0 \\
& ARR2 & Arabidopsis thaliana & BAA74528.1 & 1 & 0 \\
\hline
\end{tabular}


reads, originated from different cDNA libraries mostly from fruits, but also from seeds, infected and non-infected leaves and bark. It seems the ETR-like contigs mostly represent expression within healthy plant tissues (especially fruits) and only in a few cases they originated from Xylella fastidiosa, Citrus tristeza virus (CTV) or Phytophthora spp. infected tissues. This is consistent with the fact that the ethylene transduction pathway is activated both during fruit ripening and biotic stresses. Moreover, the majority of the ETR-like contigs were from Citrus sinensis origin, and secondarily from either Citrus reticulata or Poncirus trifoliata. None of the citrus ETR-like contigs presented a complete sequence when aligned with their best hit in Blast searches. Interestingly, the sequence of the contig encoding for a citrus ERS1 was $99 \%$ identical to a sequence of $C$. sinensis previously described. No ETR2-like or ERS2-like receptors were observed within the CitEST database. Further studies are necessary to better characterize the complete family of ethylene receptors of citrus species and their expression pattern during plant development and under stress conditions.

Analyses of the CitEST database revealed 6 unique reads related to CTR1, clusterized into 1 contig and 4 singlets (Table 3). Interestingly, these 4 singlets were all originated from $C$. reticulata cDNA libraries: 1 singlet from a fruit library and 3 singlets from a Xylella fastiosa-infected leaf library. The only citrus CTR1-like contig, originated from Citrus aurantifolia leaves, encodes an incomplete ORF (Table 3).

There were 22 unique reads related to EIN2 within the CitEST database, clusterized into 3 contigs and 1 singlet (Table 3). The citrus EIN2-like contigs are formed from various cDNA libraries, mostly from $C$. sinensis, but also from $C$. retiulata, C. aurantium and $P$. trifoliata. These contigs represent EIN2 sequences expressed in fruits, $P h y$ tophthora sp.-infected bark, healthy leaves, Xylella fastidiosa- or CTV-infected leaves, which are most homologous to EIN2 proteins from Petunia $\mathrm{x}$ hybrida and Lycopersicum esculentum.

In Arabidopsis, there are 6 members of the EIN 3 family, where EIN3 and EIL1 are the most thoroughly related ones (Alonso et al., 2003). We found 55 EIN3-like unique reads within the CitEST database clusterized into 4 contigs and 6 singlets (Table 3). These 6 singlets encode incomplete ORFs from C. sinensis, C. reticulata and C. latifolia, either leaves or fruits reads. Most of the contigs originated from $C$. sinensis and C. reticulata, infrequently from $P$. trifoliata, and notably, also from leaves infected with Xylella fastidiosa and fruits of healthy plants.

Among the main ethylene signaling pathway genes, the EREBP-like transcription factors were the most abundant within the CitEST database. A total of 159 unique reads related to EREBP-like proteins were found within the CitEST database and clusterized into 20 contigs and 14 singlets (Table 3 ). There were 6 singlets encoding incom- plete ERF-like ORFs from C. sinensis, C. reticulata, $C$. latifolia and $P$. trifoliata, from fruits, seeds, but mostly from either healthy or $X$. fastidiosa-infected leaves. Among the 11 citrus ERF-like contigs, only 4 ERF-like contigs seem complete. The 8 EREBP-like singlets found within CitEST encode incomplete ORFs from $C$. sinensis or $C$. reticulata, from either fruits or leaves. Searches within the CitEST revealed 9 citrus EREBP-like contigs, among which only the contigs homologous to the Arabidopsis EREBP-like factors (gb|AAM64362, emb|CAB96654 and ref(NP 197901) seem complete. The ERF-like and EREBP-like contigs originated from a large variety of citrus species and plant organs, either under no stress or under biotic stress situations.

In conclusion, the CitEST database is fairly representative for ethylene signaling pathway genes. Despite the fact that most of the sequences found within the CitEST database do not correspond to a complete ORF, there are several members related to each of the pathway steps (Figure 1C). In general, the ethylene signaling genes present in the CitEST database represent expression that is consistent with the many physiological processes and responses associated with this transduction pathway within both healthy plant tissues, as well as in tissues under biotic stress. Further investment is necessary to clone complete citrus ethylene signaling sequences, validate them and better characterize their expression patterns during plant development and under stress conditions.

\section{ABA signaling pathway in Citrus}

The role of sugar and phytohormones such as ABA and ethylene has been investigated in citrus, and several important functions have been attributed to these compounds. Crosstalk between sugar, ABA and ethylene pathways has been proposed; however, only a few genes involved in the signaling have been previously reported. The signal transduction that leads to the multiple responses regulated by ABA has been revealed through genetic and physiological analyses in the plant model Arabidopsis thaliana. In these studies, several different genes have been associated with the ABA response including era 1 , which encodes the betasubunit of protein farnesyltransferase (PFT) and PGGT-I (Johnson et al., 2005), the gene encoding the beta-subunit of protein geranylgeranyltransferase type I (PGGT I). These genes are involved in protein prenylation and their products may be partially redundant in the ABA response (Johnson et al., 2005). Inositol 1,4,5-triphosphate dephosphorylation is also important in this signal transduction since mutation in fry 1, the inositol polyphosphate 1-phosphatase encoding gene, leads to super-induction of ABAand stress-responsive genes (Xiong et al., 2002). Other genes involved in the ABA response participate in the RNA metabolism like $h y l 1$, a gene encoding a double-stranded RNA binding protein that is related to activity of MAP kinases (Lu et al., 2002); abh1 (Hugouvieux et al., 2001), a 
Table 3 - Ortholog genes of Ethylene signaling pathways found in the Citrus EST database.

\begin{tabular}{|c|c|c|c|c|c|c|}
\hline \multirow[t]{2}{*}{ 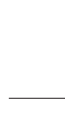 } & \multirow[t]{2}{*}{ Gene } & \multirow[t]{2}{*}{ Gene product } & \multirow[t]{2}{*}{ Organism } & \multirow[t]{2}{*}{ Accession \# } & \multicolumn{2}{|c|}{ Clusters } \\
\hline & & & & & Contigs & Singlets \\
\hline \multirow{46}{*}{ 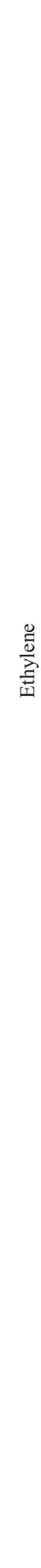 } & & ETR1 & Mangifera indica & $\mathrm{gb} \mid$ AAF61919 & 2 & 0 \\
\hline & & & Pyrus communis & gb|AAL66207 & 0 & 1 \\
\hline & ETR-like $^{1}$ & ETR5 & Lycopersicon esculentum & $\mathrm{gb} \mid \mathrm{AAU} 34077$ & 1 & 0 \\
\hline & & ERS1 & Citrus sinensis & gb|AAC99435 & 1 & 1 \\
\hline & & EIN4 & Fragaria $\mathrm{x}$ ananassa & emb|CAC48386 & 1 & 0 \\
\hline & $C T D 12$ & & Pyrus communis & $\mathrm{gb} \mid$ AAL66190 & 1 & 0 \\
\hline & CIRI & CIRI & Rosa hybrid cultivar & $\mathrm{gb} \mid \mathrm{AAK} 40361$ & 0 & 4 \\
\hline & & & Petunia x hybrida & $\mathrm{gb} \mid$ AAR08678 & 2 & 0 \\
\hline & $\mathrm{EIN} 2^{3}$ & EIN2 & Lycopersicon esculentum & $\mathrm{gb} \mid$ AAS67011 & 1 & 0 \\
\hline & & & Arabidopsis thaliana & $\mathrm{gb} \mid \mathrm{NP} \_195948$ & 0 & 1 \\
\hline & & & Fagus sylvatica & emb|CAC09582 & 1 & 0 \\
\hline & & & Cucumis melo & $\mathrm{dbj} \mid \mathrm{BAB} 64344$ & 1 & 0 \\
\hline & & EIN3 & Cucumis melo & $\mathrm{dbj} \mid \mathrm{BAB} 64345$ & 2 & 0 \\
\hline & EIN3-like & & Cucumis melo & dbj|BAB64345 & 0 & 3 \\
\hline & & $\mathrm{EIL1}^{4}$ & Nicotiana tabacum & gb|AAP03997 & 0 & 1 \\
\hline & & EIL4 & Nicotiana tabacum & gb|AAP04000 & 0 & 1 \\
\hline & & EIL2 & Lycopersicon esculentum & $\mathrm{gb} \mid \mathrm{AAK} 58858$ & 0 & 1 \\
\hline & \multirow{29}{*}{ EREBP-like $^{5}$} & \multirow{12}{*}{$\mathrm{ERF}^{6}$} & Fagus sylvatica & emb|CAE54591 & 3 & 0 \\
\hline & & & Cucumis melo & $\mathrm{dbj} \mid \mathrm{BAD} 01556$ & 1 & 0 \\
\hline & & & Lycopersicon esculentum & gb|AAS72389 & 1 & 0 \\
\hline & & & Nicotiana sylvestris & sp|Q9LW49 & 1 & 0 \\
\hline & & & Nicotiana sp. & sp|Q9SXS8 & 1 & 0 \\
\hline & & & Gossypium hirsutum & $\mathrm{gb} \mid$ AAV51937 & 2 & 2 \\
\hline & & & Gossypium hirsutum & $\mathrm{gb} \mid$ AAV51938 & 1 & 0 \\
\hline & & & Gossypium hirsutum & $\mathrm{gb} \mid \mathrm{AAO} 59439$ & 1 & 0 \\
\hline & & & Gossypium barbadense & $\mathrm{gb} \mid$ AAT77191 & 0 & 1 \\
\hline & & & Arabidopsis thaliana & ref|NP_182011 & 0 & 1 \\
\hline & & & Nicotiana tabacum & sp|Q9SXS8 & 0 & 1 \\
\hline & & & Vitis aestivalis & gb|AAQ96342 & 0 & 1 \\
\hline & & \multirow{17}{*}{ EREBP } & Lycopersicon esculentum & $\mathrm{gb} \mid \mathrm{AAC} 49740$ & 1 & 0 \\
\hline & & & Nicotiana tabacum & pir|T03927 & 1 & 0 \\
\hline & & & Nicotiana tabacum & dbj|BAA07324 & 1 & 0 \\
\hline & & & Arabidopsis thaliana & $\mathrm{gb} \mid$ AAM64362 & 1 & 0 \\
\hline & & & Arabidopsis thaliana & dbj|BAA97157 & 1 & 0 \\
\hline & & & Arabidopsis thaliana & emb|CAB96654 & 1 & 0 \\
\hline & & & Arabidopsis thaliana & ref|NP_197901 & 1 & 0 \\
\hline & & & Arabidopsis thaliana & $\mathrm{gb} \mid \mathrm{AAO} 00938$ & 1 & 0 \\
\hline & & & Arabidopsis thaliana & gb|AAM65925 & 1 & 0 \\
\hline & & & Arabidopsis thaliana & gb|AAM14242 & 0 & 1 \\
\hline & & & Arabidopsis thaliana & gb|AAP06820 & 0 & 1 \\
\hline & & & Arabidopsis thaliana & ref|NP_568755 & 0 & 1 \\
\hline & & & Arabidopsis thaliana & ref|NP_177022 & 0 & 1 \\
\hline & & & Arabidopsis thaliana & ref|NP_196348 & 0 & 1 \\
\hline & & & Arabidopsis thaliana & ref|NP_196895 & 0 & 1 \\
\hline & & & Oryza sativa & emb|CAE05154.2 & 0 & 1 \\
\hline & & & Mesembryanthemum crystallinum & $\mathrm{gb} \mid \mathrm{AAP} 80810$ & 0 & 1 \\
\hline
\end{tabular}

${ }^{1}$ Ethylene receptor. ${ }^{2}$ Constituive triple response. ${ }^{3}$ Ethylene insensitive. ${ }^{4}$ Ethylene insensitive 3-like. ${ }^{5}$ Ethylene response element binding protein-like. ${ }^{6}$ Ethylene response factor. 
gene encoding an mRNA cap binding protein that modulates the ABA signaling by affecting transcription of early ABA signaling elements; and sad 1 , that encodes a polypeptide similar to multifunctional Sm-like snRNP proteins required for mRNA splicing, export and degradation (Xiong et al., 2002). A protein that works as a receptor for ABA, encoded by the $f c a$ gene has recently been identified and is related to the control of flowering time in Arabidopsis thaliana (Razem et al., 2006). Several genes were found in the Citrus EST database (Table 4) and some are shown in Figure 1D.

The involvement of ethylene and ABA in citrus leaf abscission has also been reported. It has been proposed that leaf abscission enhancement induced by ABA can result from the direct effect of ABA on ethylene biosynthesis. This process occurs when citrus plants are rewatered after a period of water stress. ABA, the primary sensitive signal to water stress, accumulates in the roots and modulates the synthesis of root 1-aminocyclopropane-1-carboxylic acid

Table 4 - Ortholog genes of Abscisic acid signaling pathways found in the Citrus EST database.

\begin{tabular}{|c|c|c|c|c|c|c|}
\hline \multirow[t]{2}{*}{ Path } & \multirow[t]{2}{*}{ Gene } & \multirow[t]{2}{*}{ Gene product } & \multirow[t]{2}{*}{ Organism } & \multirow[t]{2}{*}{ Accession \# } & \multicolumn{2}{|c|}{ Clusters } \\
\hline & & & & & Contigs & Singlets \\
\hline \multirow{34}{*}{ 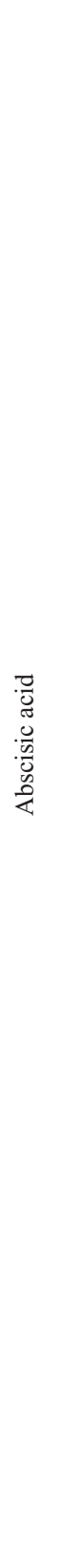 } & $\mathrm{rbohD} / \mathrm{F}$ & NADPH oxidase & Nicotiana tabacum & gi|20805911| & 1 & 4 \\
\hline & abi8/kob1 & SDL-1 & Nicotiana plumbaginifolia & emb|CAD21166.1| & 3 & 3 \\
\hline & abh1 & CBP80 & Arabidopsis thaliana & gb|AAF76167.1| & 2 & 1 \\
\hline & sad1 & SM protein & Arabidopsis thaliana & gb|AAM65292.1| & 2 & 1 \\
\hline & gpa1 & G protein & Lotus corniculatus & emb|CAA54467.1| & 1 & 1 \\
\hline & \multirow{3}{*}{ gpa2 } & \multirow{3}{*}{ G protein } & Arabidopsis thaliana & $\mathrm{gb}|\mathrm{AAC} 23761.2|$ & 1 & 0 \\
\hline & & & Arabidopsis thaliana & ref|NP_174475.1 & 1 & 0 \\
\hline & & & Arabidopsis thaliana & gi|3201682| & 0 & 1 \\
\hline & \multirow[b]{2}{*}{$\operatorname{ren} 1$} & \multirow[b]{2}{*}{$\mathrm{PP} 2 \mathrm{~A}$} & Arabidopsis thaliana & $\mathrm{gb}|\mathrm{AAP} 37715.1|$ & 2 & 0 \\
\hline & & & Medicago sativa & gi|11094365| & 0 & 3 \\
\hline & \multirow{7}{*}{ ost1 } & \multirow{7}{*}{ kinase } & Oryza sativa & $\mathrm{gb} \mid \mathrm{AAO} 65504.1$ & 3 & 0 \\
\hline & & & Fagus sylvatica & emb|CAE54075.1| & 1 & 0 \\
\hline & & & Nicotiana tabacum & gb|AAL89456.1| & 1 & 0 \\
\hline & & & Arabidopsis thaliana & $\mathrm{dbj}|\mathrm{BAB} 08630.1|$ & 1 & 0 \\
\hline & & & Oryza sativa & $\mathrm{gb}|\mathrm{AAP} 55046.1|$ & 1 & 0 \\
\hline & & & Arabidopsis thaliana & emb|CAC87047.1| & 1 & 0 \\
\hline & & & Vitis vinifera & gi $|11138330|$ & 0 & 1 \\
\hline & era1 & farnesyltransferase beta subunit & Catharanthus roseus & $\mathrm{gb}|\mathrm{AAQ} 02809.1|$ & 1 & 0 \\
\hline & fry1 & 3'(2'),5'-bisphosphate nucleotidase & Arabidopsis thaliana & dbj|BAA96901.1| & 2 & 1 \\
\hline & \multirow[b]{2}{*}{ hyl1 } & \multirow[b]{2}{*}{ double-stranded RNA-binding protein } & Arabidopsis thaliana & dbj|BAB01188.1| & 2 & 1 \\
\hline & & & Oryza sativa & ref|XP_482139.1| & 1 & 0 \\
\hline & \multirow{6}{*}{ gca2 } & \multirow{6}{*}{ SF16 protein } & \multirow{3}{*}{ Arabidopsis thaliana } & gi $|22135900|$ & 1 & 0 \\
\hline & & & & $\mathrm{gb}|\mathrm{AAO} 64059.1|$ & 1 & 0 \\
\hline & & & & $\mathrm{gb}|\mathrm{AAN} 18171.1|$ & 1 & 0 \\
\hline & & & Oryza sativa & $\mathrm{gb}|\mathrm{AAV} 33309.1|$ & 1 & 0 \\
\hline & & & \multirow{2}{*}{ Arabidopsis thaliana } & gi|11994738| & 0 & 1 \\
\hline & & & & gi $|15237584|$ & 0 & 1 \\
\hline & \multirow{2}{*}{ ggb } & \multirow{2}{*}{ geranylgeranyltransferase I } & Glycine $\max$ & $\mathrm{gb}|\mathrm{AAQ} 62584.1|$ & 1 & 0 \\
\hline & & & Arabidopsis thaliana & gb|AAP37823.1| & 1 & 0 \\
\hline & \multirow{2}{*}{ gcr1 } & \multirow{2}{*}{ G-protein-coupled receptor } & Arabidopsis thaliana & $\mathrm{gb}|\mathrm{AAD} 49769.1|$ & 1 & 0 \\
\hline & & & Arabidopsis thaliana & gi $|15221138|$ & 0 & 1 \\
\hline & \multirow{3}{*}{ fca } & \multirow{3}{*}{ Flowering time control protein } & Arabidopsis thaliana & emb $|\mathrm{CAB} 78672.1|$ & 1 & 0 \\
\hline & & & Arabidopsis thaliana & gi|30690648| & 0 & 1 \\
\hline & & & Arabidopsis thaliana & gi|2204089| & 0 & 1 \\
\hline
\end{tabular}


(ACC) and the increase in ethylene that triggers the events leading to leaf abscission (Katz et al., 2004).

\section{Sugar signaling pathways in Citrus}

In the Citrus EST database, several genes involved in sugar sensing and signaling were found, including HXK, FRK, SnRK and SNF4 (Table 5). All organisms need to adapt to sugar availability, which is achieved by the ability to respond to sugar levels or flux. Sugar signaling pathways are part of cellular regulatory networks and do not function in isolation. Recent studies have shown evidence of interactions between sugar and phytohormone response; however, little is known about the mechanisms by which different response pathways interact. The function of each sugar signaling gene identified in CitEST must be further investigated in experimental studies in order to associate them to specific biological conditions.

\section{Jasmonic acid signaling pathway in Citrus}

Jasmonate mediates many transcriptional responses in plants related to wounding and pathogenesis by acting as potent regulators for the expression of numerous frontline immune response genes, including those for defensins and antifungal proteins. Two multiprotein complexes, COP9 signalosome (CNS) and the SCF (COI1), both play a central role in jasmonate signaling. The JA pathway has been identified through mutant screening. It has been suggested that JA signaling starts with exogenous and endogenous elicitors that lead to JA synthesis. Once JA sensors are activated an intricate network is switched on and as a result JA signaling targets cell response with defense mechanisms through PR protein transcription (Liechti and Farmer, 2006).

In the citrus EST database, some of the genes involved in JA signaling were found (Table 6). Most ESTs were expressed in $X$. fastidiosa-infected or fruit development libraries. Only one read showing similarity to COI1 was encountered in the $X$. fastidiosa-infected library and the citrus sequence showed $78 \%$ identity to the COI1 of $A$. thaliana. These results provide another key to understanding the fine control of gene expression in immune responses, and indicate that JA might have a fundamental role in the initiation and maintenance of long-distance signal

Table 5 - Ortholog genes of sugar signaling pathways found in the Citrus EST database.

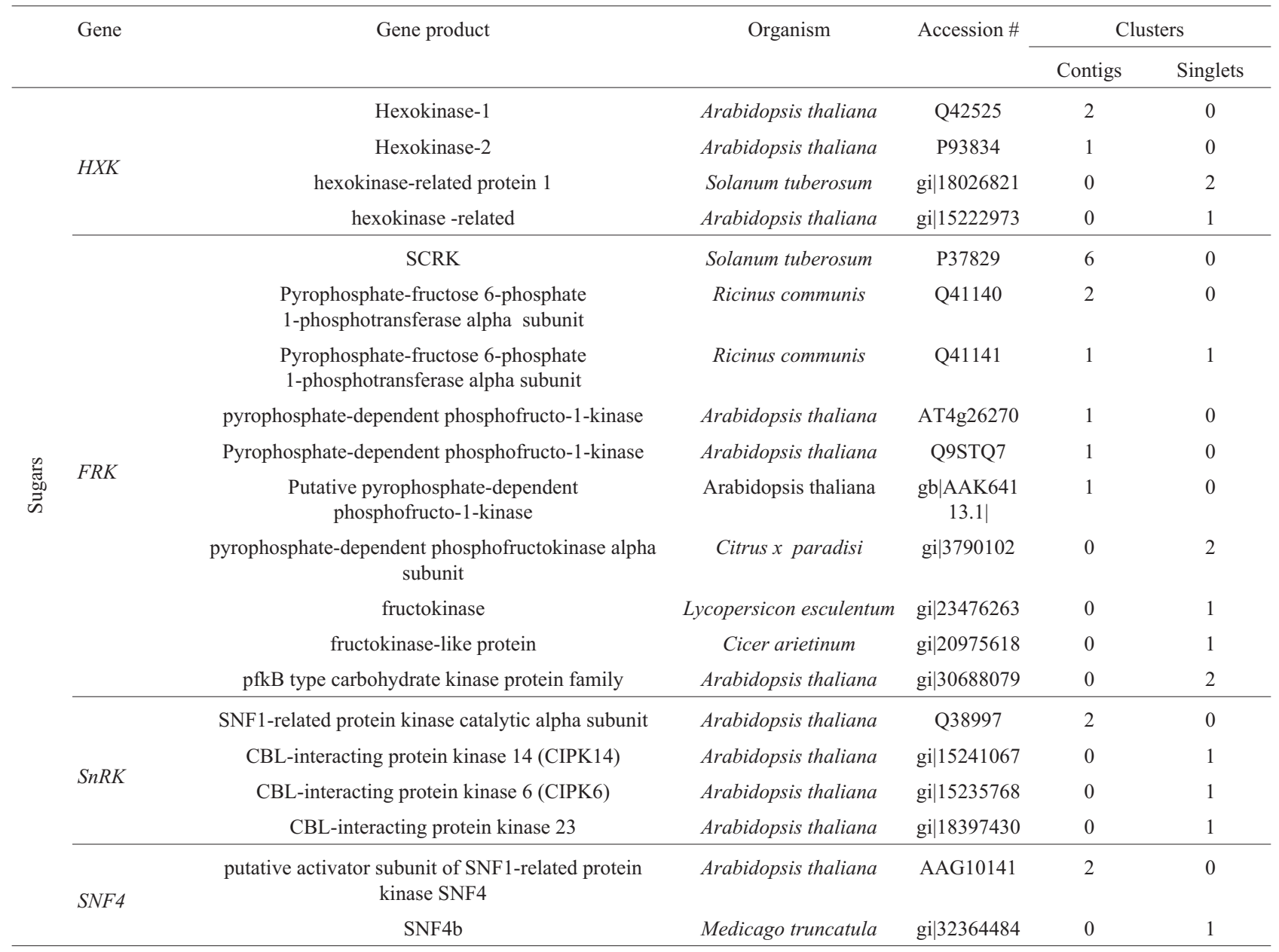


transfer in response to wounding, regulation of fertility, among other processes.

\section{COP9 in Citrus}

The CSN complex participates in multifaceted cellular processes including regulation of plant development and ubiquitin-mediated proteolysis. Furthermore, the COP9 signalosome shares homologies with the lid subcomplex of the proteasome and is evolutionarily conserved from fission yeast to humans. In the citrus EST database, we investigated the presence of ortholog genes and COP9 similar sequences. Consistent with this possibility, several contigs and singlets among 70 reads in the databank were found (Table 7). All components of COP9 multicomplex were identified but only the sequence encoding to CSN4 gene was full-length. All reads were equally distributed among the cDNA libraries. Our findings suggest that in Citrus the COP9 might have an important role in development and other cellular functions.

The COP9 signalosome (CSN) has been implicated in two distinct processes: regulation of protein degradation through deneddylation of the cullin subunit of multiple

Table 6 - Ortholog genes of Jasmonic Acid signaling pathways found in the Citrus EST database.

\begin{tabular}{|c|c|c|c|c|c|c|}
\hline \multirow[t]{2}{*}{ 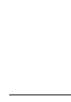 } & Gene & \multirow[t]{2}{*}{ Gene product } & \multirow[t]{2}{*}{ Organism } & \multirow[t]{2}{*}{ Accession \# } & \multicolumn{2}{|c|}{ Clusters } \\
\hline & & & & & Contigs & Singlets \\
\hline \multirow{21}{*}{ 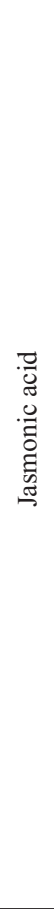 } & COL1 & Coronatine insensitive 1 & Arabidopsis thaliana & gi|18405209 & 0 & 1 \\
\hline & $S K P 1$ & Skp1-related protein & Arabidopsis thaliana & Atlg75950 & 1 & 0 \\
\hline & & Skp1 & Capsicum annuum & gi|62467589 & 1 & 0 \\
\hline & & Skp1 & Medicago sativa & gi|4959710 & 1 & 0 \\
\hline & & SKP1 & Nicotiana tabacum & gi|51292007 & 1 & 0 \\
\hline & & Skp1/Ask1-like protein & Zantedeschia hybrid cultivar & gi|47176688 & 1 & 0 \\
\hline & & SKP1 & Brassica napus & gi|81248477 & 1 & 0 \\
\hline & & SKP1 family protein & Arabidopsis thaliana & gi|18411999 & 0 & 1 \\
\hline & $C U L 1$ & Cullin-1 & Arabidopsis thaliana & Q94AH6 & 2 & 0 \\
\hline & & putative cullin & Arabidopsis thaliana & $\mathrm{gb} \mid \mathrm{AAM} 14063.1$ & 1 & 0 \\
\hline & & putative cullin 3 & Oryza sativa & XP_467770.1 & 2 & 0 \\
\hline & & putative cullin protein & Olea europaea & $\mathrm{gb} \mid \mathrm{AAL} 27655.2$ & 1 & 0 \\
\hline & & cullin, putative & Arabidopsis thaliana & NP_177125.1 & 1 & 0 \\
\hline & & Putative cullin & Oryza sativa & gi|14091839 & 0 & 1 \\
\hline & & CUL1 & Oryza sativa & gi|54290813 & 0 & 1 \\
\hline & & cullin-like protein 1 & Pisum sativum & gi|22335691 & 0 & 2 \\
\hline & & cullin 1 protein -related & Arabidopsis thaliana & gi|18411983 & 0 & 1 \\
\hline & & putative cullin & Arabidopsis thaliana & gi|20268719 & 0 & 1 \\
\hline & & cullin-like protein & Oryza sativa & gi|34914728 & 0 & 1 \\
\hline & $R B X 1 A$ & RING-box protein 1a (RBX1a-At) & Arabidopsis thaliana & Q940X7 & 1 & 0 \\
\hline & & ring-box protein - like & Arabidopsis thaliana & gi|18420256 & 0 & 1 \\
\hline
\end{tabular}

Table 7 - Ortholog genes of COP9 signalosome pathways found in the Citrus EST database.

\begin{tabular}{|c|c|c|c|c|c|c|}
\hline & \multirow[t]{2}{*}{ Gene } & \multirow[t]{2}{*}{ Gene product } & \multirow[t]{2}{*}{ Organism } & \multirow[t]{2}{*}{ Accession \# } & \multicolumn{2}{|c|}{ Clusters } \\
\hline & & & & & Contigs & Singlets \\
\hline \multirow{9}{*}{ 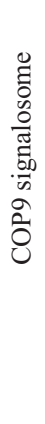 } & CSN1 FUS1 & Csn1 & Arabidopsis thaliana & $\mathrm{gb} \mid \mathrm{AAK} 93733.1$ & 1 & 0 \\
\hline & CSN2 & Csn2 & Oryza sativa & $\mathrm{dbj} \mid \mathrm{BAD} 81083.1$ & 1 & 1 \\
\hline & CSN3 & Csn3 & $\begin{array}{c}\text { Nicotiana benthamiana } \\
\text { Oryza sativa }\end{array}$ & $\begin{array}{l}\mathrm{gb} \mid \text { AAOO85512.1 } \\
\text { ref|XP_479811.1 }\end{array}$ & 2 & 0 \\
\hline & CSN4 & $\mathrm{Csn} 4 / \mathrm{COP} 8$ & Arabidopsis thaliana & $\mathrm{gb}|\mathrm{AAL} 58103.1|$ & 1 & 0 \\
\hline & CSN 5 & Csn5a & Lycopersicon esculentum & $\mathrm{gb} \mid \mathrm{AAG} 43411.1$ & 1 & 0 \\
\hline & CSNS & Csn5b/ Fusca 5 & Arabidopsis thaliana & AT1G71230 & 1 & 1 \\
\hline & CSN6 & Csn6 & Arabidopsis thaliana & AT5g56280 & 1 & 0 \\
\hline & CSN7 & Csn7 & Arabidopsis thaliana & At1g02090 & 2 & 0 \\
\hline & CSN8 & Cns8/ FUS4 & Arabidopsis thaliana & NP_199111.1 & 1 & 0 \\
\hline
\end{tabular}


SCF (Skpl/cullin/F-box) E3-ubiquitin ligases and modulation of kinase signaling pathways through associated kinases. Although the clear mechanism of action of COP9 is not yet clarified, it has been demonstrated in Arabidopsis seedling that COP9 genes play a key role in the light control of development, integrating light signals and modulating developmental pattern formation (Chamovitz and Yahalom, 2003). In this study, the authors have systematically investigated COP/DET/FUS-controlled genome expression during Arabidopsis seedling development using a cDNA microarray.

COP9 is an intriguing subject of study and many questions remain in our findings. Further studies would be necessary to clarify the role of COP9 in Citrus.

\section{Kinases and phosphatases in Citrus}

Analyses of the Arabidopsis genome show 20 genes that might encode MAPKs, 10 genes that appear to encode MAPKKs and more than 60 genes possibly encoding MAPKKK homologs (Champion et al., 2004).

In CitEST, we did find contigs and singlets related to different MAP kinases (Table 8), including the tobacco NPK1 (MAPKKK), NQK1 (MAPKK) and NRK1 (MAPK) which is the cascade involved in the regulation of cytokinesis in plant cells (Soyano et al., 2003), the YDA MAPKK kinase that plays a key role in the early development of Arabidopsis embryos (Lukowitz et al., 2004), and the tobacco WIPK (wounding-induced protein kinase)

Table 8 - Ortholog genes of kinase and phosphatase signaling pathways found in the Citrus EST database.

\begin{tabular}{|c|c|c|c|c|c|c|}
\hline & \multirow[t]{2}{*}{ Gene } & \multirow[t]{2}{*}{ Gene product } & \multirow[t]{2}{*}{ Organism } & \multirow[t]{2}{*}{ Accession \# } & \multicolumn{2}{|c|}{ Clusters } \\
\hline & & & & & Contigs & Singlets \\
\hline \multirow{36}{*}{ 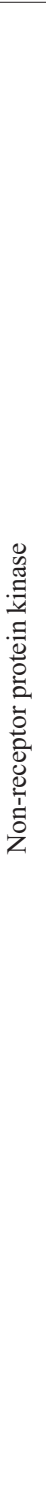 } & \multirow{14}{*}{ MAPK } & AtMPK3 & Arabidopsis thaliana & Q39023 & 1 & 0 \\
\hline & & ATMPK18 & Arabidopsis thaliana & NP_175756 & 0 & 1 \\
\hline & & MAPK & Medicago sativa & AAD28617 & 2 & 0 \\
\hline & & MAPK2 & Glycine max & AAQ14867 & 1 & 0 \\
\hline & & MAPK7 & Oryza sativa & BAD61401 & 1 & 0 \\
\hline & & MAP kinase & Arabidopsis thaliana & D84859 & 1 & 0 \\
\hline & & MAP kinase 4 & Petroselinum crispum & AAN65180 & 2 & 0 \\
\hline & & MPK8 & Arabidopsis thaliana & NP_173253 & 0 & 1 \\
\hline & & MPK 17 & Arabidopsis thaliana & AAP21277 & 1 & 0 \\
\hline & & MPK9 & Brassica napus & AAU95462 & 1 & 0 \\
\hline & & NRK1 & Nicotiana tabacum & BAB32406 & 1 & 0 \\
\hline & & NTF6 & Nicotiana tabacum & Q40531 & 0 & 1 \\
\hline & & RMAPK1 & Oryza sativa & AAF23902 & 0 & 1 \\
\hline & & WIPK & Nicotiana tabacum & BAB79636 & 1 & 0 \\
\hline & \multirow{2}{*}{ MAPKK } & MAPKK & Lycopersicon esculentum & AAU04436 & 2 & 0 \\
\hline & & NQK1 MAPKK & Nicotiana tabacum & BAB32405 & 1 & 0 \\
\hline & \multirow{20}{*}{ MAPKKK } & CTR1 & Arabidopsis thaliana & CAB82938 & 1 & 0 \\
\hline & & CTR1 & Brassica juncea & AAP86285 & 0 & 1 \\
\hline & & CTR1 & Brassica juncea & AAP86286 & 3 & 1 \\
\hline & & CTR1 & Oryza sativa & BAC79157 & 0 & 1 \\
\hline & & CTR1 & Oryza sativa & BAD28881 & 1 & 0 \\
\hline & & CTR1 & Oryza sativa & BAD37611 & 4 & 1 \\
\hline & & CTR1 & Oryza sativa & $X P \_450193$ & 13 & 0 \\
\hline & & CTR1 & Rosa hybrid cultivar & AAK40361 & 2 & 3 \\
\hline & & EDR1 & Arabidopsis thaliana & AAG31143 & 0 & 2 \\
\hline & & MAP3K & Arabidopsis thaliana & D85436 & 0 & 1 \\
\hline & & MAP3K alpha 1 & Oryza sativa & BAD27776 & 1 & 0 \\
\hline & & MAP3K delta-1 & Arabidopsis thaliana & CAA74591 & 0 & 1 \\
\hline & & MAP3K delta-1 & Arabidopsis thaliana & CAB87658 & 1 & 0 \\
\hline & & MAP3K delta-1 & Arabidopsis thaliana & NP_196746 & 0 & 1 \\
\hline & & MAP3K delta-1 & Oryza sativa & $X P \_464691$ & 1 & 0 \\
\hline & & MAP3K epsilon & Arabidopsis thaliana & BAB 01760 & 2 & 0 \\
\hline & & MAP3K epsilon 1 & Brassica napus & CAB54520 & 0 & 1 \\
\hline & & MAP3K gamma & Arabidopsis thaliana & CAA74696 & 3 & 0 \\
\hline & & MEK kinase & Arabidopsis thaliana & AAD10848 & 0 & 2 \\
\hline & & MEKK1 & Arabidopsis thaliana & CAB77975 & 2 & 0 \\
\hline
\end{tabular}


Table 8 (cont.)

\begin{tabular}{|c|c|c|c|c|c|c|}
\hline & \multirow[t]{2}{*}{ Gene } & \multirow[t]{2}{*}{ Gene product } & \multirow[t]{2}{*}{ Organism } & \multirow[t]{2}{*}{ Accession \# } & \multicolumn{2}{|c|}{ Clusters } \\
\hline & & & & & Contigs & Singlets \\
\hline \multirow{39}{*}{ 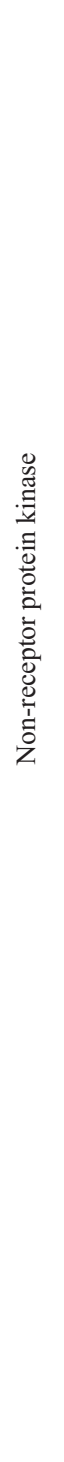 } & \multirow{7}{*}{ MAPKKK } & mekk1 & Medicago sativa & CAE00640 & 1 & 0 \\
\hline & & NPK1-related protein kinase 2 & Arabidopsis thaliana & BAA21856 & 1 & 0 \\
\hline & & YDA & Arabidopsis thaliana & AAR10436 & 2 & 0 \\
\hline & & MAP kinase & Arabidopsis thaliana & BAB01779 & 1 & 0 \\
\hline & & mitogen-activated protein kinase & Nicotiana tabacum & AAQ83971 & 1 & 0 \\
\hline & & similar to MAP/ERK kinase kinase 3 gi| 4505153 & Arabidopsis thaliana & NP_175344 & 0 & 2 \\
\hline & & ZIK1 & Medicago sativa & CAC84087 & 13 & 5 \\
\hline & At2g20040 & cAMP-dependent protein kinase - catalytic & Arabidopsis thaliana & AAD24392 & 1 & 0 \\
\hline & DWARF12 & glycogen synthase kinase 3 beta protein kinase & Arabidopsis thaliana & AAN71719 & 1 & 1 \\
\hline & GSK1 & GSK3 & Arabidopsis thaliana & AAB71545 & 0 & 1 \\
\hline & GSK-3 & glycogen synthase kinase 3 & Medicago sativa & CAC08564 & 1 & 1 \\
\hline & GSK-3 & GSK-3-like protein MsK4 & Medicago sativa & AAN63591 & 4 & 0 \\
\hline & MSK-1 & Glycogen synthase kinase-3 homolog MsK-1 & Medicago sativa & P51137 & 0 & 3 \\
\hline & MSK-3 & protein kinase MSK-3-like & Arabidopsis thaliana & CAB87631 & 2 & 3 \\
\hline & MSK-3 & Glycogen synthase kinase-3 homolog MsK-3 & Medicago sativa & P51139 & 3 & 1 \\
\hline & AT4G28880 & casein kinase I & Arabidopsis thaliana & NP_194617 & 1 & 0 \\
\hline & At3g13670 & putative casein kinase & Arabidopsis thaliana & AAM51279 & 8 & 3 \\
\hline & P0510F09.20 & putative casein kinase I & Oryza sativa & NM_191682 & 6 & 1 \\
\hline & CKA1 & casein kinase II alpha chain 1 & Arabidopsis thaliana & NP_201539 & 2 & 2 \\
\hline & \multirow[b]{2}{*}{ ck2beta2 } & Casein kinase II regulatory subunit & Nicotiana tabacum & CAD32500 & 4 & 5 \\
\hline & & casein kinase II alpha subunit & Zea mays & AAF76187 & 1 & 0 \\
\hline & CIPK & CBL-interacting protein kinase & Brassica napus & AAL37170 & 2 & 0 \\
\hline & CK1 & CIPK-like protein 1 & Oryza sativa & Q6X4A2 & 2 & 0 \\
\hline & CIPK1 & CBL-interacting protein kinase 1 & Arabidopsis thaliana & NP_566580 & 4 & 1 \\
\hline & CIPK2 & CBL-interacting protein kinase 2 & Arabidopsis thaliana & AAF86506 & 1 & 0 \\
\hline & CIPK3 & CBL-interacting protein kinase 3 & Arabidopsis thaliana & NP_850093 & 0 & 1 \\
\hline & CIPK5 & CBL-interacting protein kinase 5 & Arabidopsis thaliana & NP_568241 & 2 & 0 \\
\hline & CIPK6 & CBL-interacting protein kinase 6 & Arabidopsis thaliana & NP_-194825 & 1 & 1 \\
\hline & CIPK8 & CBL-interacting protein kinase 6 & Arabidopsis thaliana & AAK 16683 & 0 & 1 \\
\hline & CIPK9 & CBL-interacting protein kinase 9 & Arabidopsis thaliana & NP_171622 & 3 & 2 \\
\hline & CIPK10 & CBL-interacting protein kinase 10 & Arabidopsis thaliana & NP_568878 & 0 & 2 \\
\hline & CIPK11 & CBL-interacting protein kinase 11 & Arabidopsis thaliana & O22932 & 1 & 0 \\
\hline & CIPK14 & CBL-interacting protein kinase 14 & Arabidopsis thaliana & AAK16689 & 0 & 1 \\
\hline & CIPK18 & CBL-interacting protein kinase 18 & Arabidopsis thaliana & NP_174217 & 1 & 0 \\
\hline & CIPK20 & CBL-interacting protein kinase 20 & Arabidopsis thaliana & NP_199394 & 1 & 1 \\
\hline & CIPK22 & CBL-interacting protein kinase 22 & Arabidopsis thaliana & NP_181383 & 1 & 0 \\
\hline & CIPK23 & CBL-interacting protein kinase 23 & Arabidopsis thaliana & NP_564353 & 2 & 2 \\
\hline & CIPK24 & CBL-interacting protein kinase 24 & Arabidopsis thaliana & AAK 72257 & 2 & 0 \\
\hline & CIPK25 & CBL-interacting protein kinase 25 & Arabidopsis thaliana & NP_568466 & 1 & 2 \\
\hline \multirow{19}{*}{ 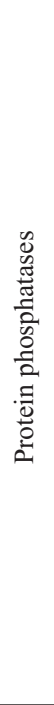 } & PP1 & protein phosphatase PP1 isozyme 2 & Arabidopsis thaliana & BAB09762 & 1 & 2 \\
\hline & PP1 & protein phosphatase PP1 & Phaseolus vulgaris & CAA88254 & 2 & 0 \\
\hline & PP1A & phosphoprotein phosphatase 1a catalytic chain & Catharanthus roseus & T09995 & 0 & 2 \\
\hline & PP1 beta & protein phosphatase 1 , catalytic beta subunit & Medicago sativa & CAA05491 & 4 & 3 \\
\hline & PP1 & protein phosphatase PP1 isozyme 4 & Arabidopsis thaliana & AAB87136 & 1 & 0 \\
\hline & $\mathrm{ZmPP} 1$ & protein phosphatase-1 & Zea mays & AAA33545 & 0 & 1 \\
\hline & $\mathrm{PP} 2 \mathrm{Ac}$ & protein phosphatase $2 \mathrm{~A}-4$ catalytic subunit & Arabidopsis thaliana & AAD10855 & 3 & 3 \\
\hline & $\mathrm{PP} 2 \mathrm{Ac} 2$ & protein phosphatase $2 \mathrm{~A}$ catalytic subunit & Lycopersicon esculentum & AAQ67226 & 3 & 0 \\
\hline & PsPP2A & serine/threonine protein phosphatase $2 \mathrm{~A}$ & Pisum sativum & AAM 21172 & 1 & 0 \\
\hline & PPX & protein phosphatase 4 catalytic & Malus $x$ domestica & CAA87385 & 1 & 0 \\
\hline & LePP5 & PP5 & Lycopersicon esculentum & AAN64317 & 1 & 1 \\
\hline & PP7 & PP7 & Arabidopsis thaliana & NP_851258 & 3 & 0 \\
\hline & PP2A & protein phosphatase $2 \mathrm{~A} 65 \mathrm{kDa}$ regulatory subunit & Arabidopsis thaliana & AAO00848 & 4 & 7 \\
\hline & PP2A & phosphatase $2 \mathrm{~A}$ regulatory A subunit & Oryza sativa & XP_450276 & 1 & 1 \\
\hline & $\mathrm{PP} 2 \mathrm{C}$ & catalytic/ protein phosphatase type $2 \mathrm{C}$ & Arabidopsis thaliana & NP_-195118 & 37 & 37 \\
\hline & $\mathrm{PP} 2 \mathrm{C}$ & protein phosphatase $2 \mathrm{C}$-like & Oryza sativa & BAD72331 & 9 & 0 \\
\hline & At5g19280 & putative kinase associated protein phosphatas & Arabidopsis thaliana & AAM51227 & 2 & 0 \\
\hline & AT1G05000 & tyrosine specific protein phosphatase family protein & Arabidopsis thaliana & NP_171993 & 2 & 0 \\
\hline & AT4G18593 & dual specificity protein phosphatase & Arabidopsis thaliana & NP_ 567561 & 0 & 4 \\
\hline
\end{tabular}


which is involved in the cascade to disease resistance (Yang et al., 2001). Only one contig is related to WIPK and shows a tendency of expression in infected leaf libraries with X. fastidiosa and Citrus tristeza virus of $C$. sinensis and $P$. trifoliata, respectively, which is consistent with its function in disease resistance (Yang et al., 2001).

In the Arabidopsis genome, 112 phosphatase catalytic subunit sequences have been identified, 69 of which are PP2Cs (Kerk et al., 2002). In the CitEST database, 36 contigs and singlets related to PPP family were found covering its major members with the exception of PP2B, which has not been detected in plants until now; and 83 contigs similar to PP2C were found (Table 8).

In CitEST, contigs and singlets related to GSK3 especially to alfalfa GSK3 were found. We also found 16 contigs similar to $\mathrm{Ck} 1$ and 7 similar to $\mathrm{Ck} 2$, and 4 singlets similar to $\mathrm{Ck} 1$ and 7 similar to $\mathrm{Ck} 2$. We did find 2 contigs related to Kinase-associated protein phosphatase in CitEST (Table 8). We also found 2 contigs and 1 singlet related to tyrosine-specific protein phosphatase protein and 1 contig and 5 singlets similar to another tyrosine phosphatase called dual-specificity protein phosphatase, which has also been implicated in the negative regulation of MAPK in Arabidopsis (Gupta et al., 2002).

\section{Inositol phosphate in Citrus}

The search in the CitEST database for enzymes involved in inositol metabolism identified components of several steps in this pathway (Table 9, Figure 2). Several contigs related to these enzymes showed high expression in leaves

Table 9 - Ortholog genes of Inositol phosphate pathways found in the Citrus EST database.

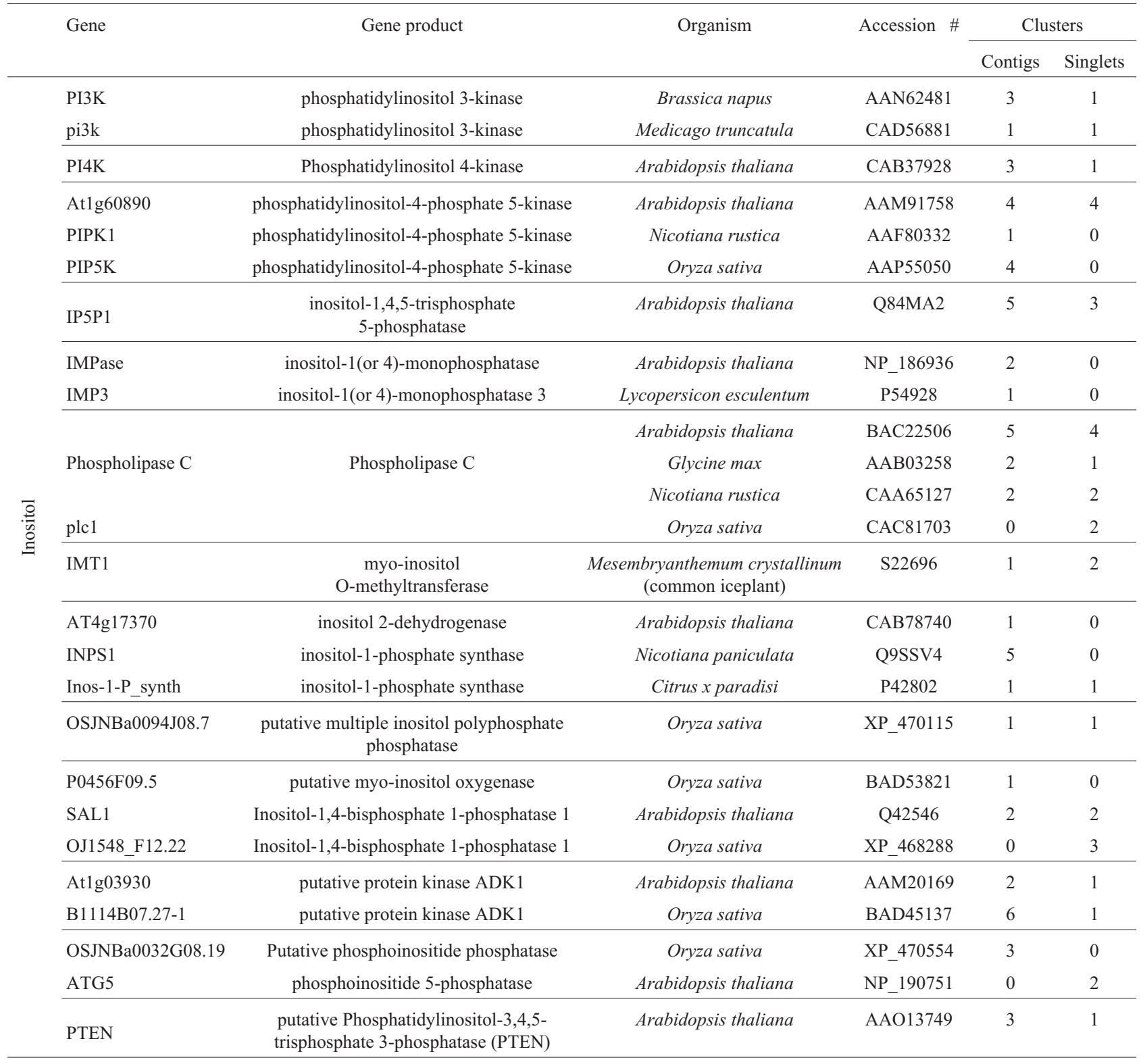




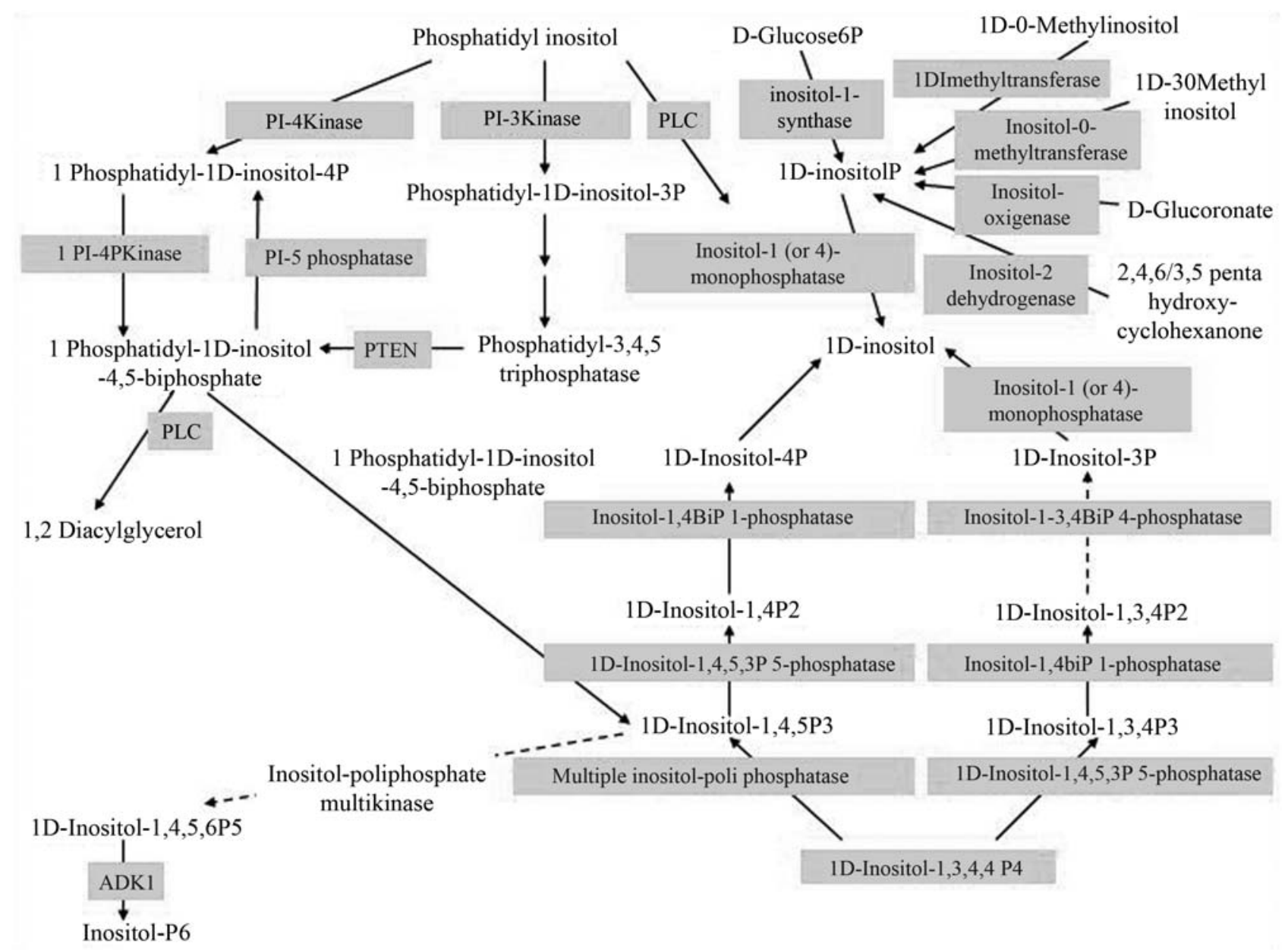

Figure 2 - Putative inositol metabolism in citrus. The enzymes for which contigs and/or singlets have been found in citrus are highlighted in gray.

and fruit libraries. Inositol has been implicated in the early signaling events of plants linking gravity sensing to the initiation of the gravitropic response. However, at present, the contribution of the phosphoinositide signaling pathway in plant gravitropism is not well understood. Recently, Liu et al. (2006) reported the role of inositol 1,4,5-trisphosphate IP(3) in transducing heat-shock (HS) signals in Arabidopsis. The authors provided the primary evidence for the possible involvement of IP(3) in HS signal transduction in higher plants. Our results suggest that the activity of the inositol pathway might reveal an important role in the cell signaling network.

In our investigation, we found one putative contig with sequence similarity to the catalytic subunit of the cyclic adenosine monophosphate (cAMP) dependent protein kinase and one singlet similar to the regulatory subunit. On the other hand, the cyclic guanidine monophosphate (cGMP) dependent protein kinase was not found in the Citrus EST database.

\section{Plant peptides in Citrus}

Although we did not find any ESTs similar to systemin, phytosulfokine and clavata3, we did find a large number of contigs and singlets for their receptors, which suggests the possible existence of these signaling peptides.

\section{Concluding Remarks}

In the present work, we report the presence of several genes involved in the signaling pathways of calcium, sugar and plant hormones in the citrus genome. These results may indicate that similar mechanisms described in other plants, such as Arabidopsis, occur in citrus. Further experimental studies must be conducted in order to understand the different signaling pathways present.

An interesting result obtained was that a high number of genes involved in the signaling pathway of ethylene were found in the CitEST database. Despite the fact that most of the sequences found within the CitEST database do not correspond to a complete ORF, there are several members related to each of the pathway steps. In general, the ethylene signaling genes present in the CitEST database represent expression within both healthy plant tissues as well as tissues under biotic stress, coherently with the several physiological processes and responses associated with this transduction pathway. 


\section{Acknowledgments}

We would like to thank FAPESP for financial support provided to Simone Guidetti-Gonzalez (Grant \# 05/581174), and also Embrapa - Genetic Resources and Biotechnology.

\section{References}

Alberti A, Lodi T, Ferrero I and Donnini C (2003) MIG1dependent and MIG1-independent regulation of GAL gene expression in Saccharomyces cerevisiae: Role of Imp2p. Yeast 20:1085-1096.

Alonso JM, Stepanova AN, Solano R, Wisman E, Ferrari S, Ausubel FM and Ecker JR (2003) Five components of the ethylene-response pathway identified in a screen for weak ethylene-insensitive mutants in Arabidopsis. Proc Natl Acad Sci USA 100:2992-2997.

Altschul SF, Madden TL, Schaffer AA, Zhang J, Zhang Z, Miller W and Lipman DJ (1997) Gapped BLAST and PSI-BLAST: A new generation of protein database search programs Nucleic Acids Res 25:3389-3402.

Boldyreff B, Meggio F, Dobrowolska G, Pinna LA and Issinger OG (1993) Expression and characterization of a recombinant maize CK-2 alpha subunit. Biochim Biophys Acta 1173:32-38.

Button DK, Gartland KM, Ball LD, Natanson L, Gartland JS and Lyon GD (2006) DRASTIC-INSIGHTS: Querying information in a plant gene expression database. Nucleic Acids Res 34:D712-D716.

Chamovitz DA and Yahalom A (2003) A systems approach to the COP9 signalosome. Plant Physiol 132:426-427.

Champion A, Picaud A and Henry Y (2004) Reassessing the MAP3K and MAP4K relationships. Trends Plant Sci 9:123-129.

Chen Z and Cobb MH (2001) Regulation of stress-responsive mitogen-activated protein (MAP) kinase pathways by TAO2. J Biol Chem 276:16070-16075.

Chilley P (2003) Polypeptide hormones: Signaling molecules in plants. Vitam Horm 66:317-344.

Devoto A, Nieto-Rostro M, Xie D, Ellis C, Harmston R, Patrick E, Davis J, Sherratt L, Coleman M and Turner JG (2002) COI1 links jasmonate signaling and fertility to the SCF ubiquitinligase complex in Arabidopsis. Plant J 32:457-466.

Dornelas MC, Van Lammeren AA and Kreis M (2000) Arabidopsis thaliana SHAGGY-related protein kinases (AtSK11 and 12) function in perianth and gynoecium development. Plant J 21:419-429.

Farmer EE, Almeras E and Krishnamurthy V (2003) Jasmonates and related oxylipins in plant responses to pathogenesis and herbivory. Curr Opin Plant Biol 6:372-378.

Guo H and Ecker JR (2004) The ethylene signaling pathway: New insights. Curr Opin Plant Biol 7:40-49.

Gupta R, Ting JT, Sokolov LN, Johnson SA and Luan S (2002) A tumor suppressor homolog, AtPTEN1, is essential for pollen development in Arabidopsis. Plant Cell 14:2495-2507.

Harper JF, Breton G and Harmon A (2004) Decoding $\mathrm{Ca}^{(2+)}$ signals through plant protein kinases. Annu Rev Plant Biol 55:263-288.

Hrabak EM, Chan CW, Gribskov M, Harper JF, Choi JH, Halford N, Kudla J, Luan S, Nimmo HG, Sussman MR, et al. (2003)
The Arabidopsis CDPK-SnRK superfamily of protein kinases. Plant Physiol 132:666-680.

Huang X and Madan A (1999) CAP3: A DNA sequence assembly program Genome Res 9:868-877.

Hugouvieux V, Kwak JM and Schroeder JI (2001) An mRNA cap binding protein, $\mathrm{ABH} 1$, modulates early abscisic acid signal transduction in Arabidopsis. Cell 106:477-487.

Johnson CD, Chary SN, Chernoff EA, Zeng Q, Running MP and Crowell DN (2005) Protein geranylgeranyltransferase I is involved in specific aspects of abscisic acid and auxin signaling in Arabidopsis. Plant Physiol 139:722-733.

Jonak C and Hirt H (2002) Glycogen synthase kinase 3/SHAGGY-like kinases in plants: An emerging family with novel functions. Trends Plant Sci 7:457-461.

Katz E, Lagunes PM, Riov J, Weiss D and Goldschmidt EE (2004) Molecular and physiological evidence suggests the existence of a system II-like pathway of ethylene production in non-climacteric Citrus fruit. Planta 219:243-52.

Kerk D, Bulgrien J, Smith DW, Barsam B, Veretnik S and Gribskov M (2002) The complement of protein phosphatase catalytic subunits encoded in the genome of Arabidopsis. Plant Physiol 129:908-925.

Kiba T, Naitou T, Koizumi N, Yamashino T, Sakakibara H and Mizuno T (2005) Combinatorial microarray analysis revealing Arabidopsis genes implicated in cytokinin responses through the His $\rightarrow$ Asp Phosphorelay circuitry. Plant Cell Physiol 46:339-355.

Klee HJ (2004) Ethylene signal transduction. Moving beyond Arabidopsis. Plant Physiol 135:660-667.

Kutuzov MA and Andreeva AV (2002) Protein Ser/Thr phosphatases with kelch-like repeat domains. Cell Signal 14:745-750.

Kwak JM, Mori IC, Pei ZM, Leonhardt N, Torres MA, Dangl JL, Bloom RE, Bodde S, Jones JD and Schroeder JI (2003) NADPH oxidase AtrbohD and AtrbohF genes function in ROS-dependent ABA signaling in Arabidopsis. EMBO J 22:2623-2633.

Liechti R and Farmer EE (2006) Jasmonate biochemical pathway. Sci STKE 2006 (322).

Ligterink W and Hirt H (2001) Mitogen-activated protein (MAP) kinase pathways in plants: Versatile signaling tools. Int Rev Cytol 201:209-275.

Liu HT, Gao F, Cui SJ, Han JL, Sun dY and Zhou RG (2006) Primary evidence for involvement of IP(3) in heat-shock signal transduction in Arabidopsis. Cell Res 16:394-400.

Liu W, Xu ZH, Luo D and Xue HW (2003) Roles of OsCKI1, a rice casein kinase I, in root development and plant hormone sensitivity. Plant J 36:189-202.

Lo WS, Duggan L, Emre NC, Belotserkovskya R, Lane WS, Shiekhattar R and Berger SL (2001) Snf1- A histone kinase that works in concert with the histone acetyltransferase Gcn5 to regulate transcription. Science 293:1142-1146.

Lorenzo O, Piqueras R, Sanchez-Serrano JJ and Solano R (2003) Ethylene response Factor 1 integrates signals from ethylene and jasmonate pathways in plant defense. Plant Cell 15:165-178

Lu C, Han MH, Guevara-Garcia A and Fedoroff NV (2002) Mitogen-activated protein kinase signaling in postgermination arrest of development by abscisic acid. Proc Natl Acad Sci USA 99:15812-15817. 
Lukowitz W, Roeder A, Parmenter D and Somerville C (2004) A MAPKK kinase gene regulates extra-embryonic cell fate in Arabidopsis. Cell 116:4-5.

Memelink J, Verpoorte R and Kijne JW (2001) ORCAnization of jasmonate-responsive gene expression in alkaloid metabolism. Trends Plant Sci 6:212-219.

Merlot S and Firtel RA (2003) Leading the way: Directional sensing through phosphatidylinositol 3-kinase and other signaling pathways. J Cell Sci 116:3471-3478.

Meskiene I, Bögre L, Glaser W, Balog J, Brandstötter M, Zwerger K, Ammerer G and Hirt H (1998) MP2C, a plant protein phosphatase $2 \mathrm{C}$, functions as a negative regulator of mitogen-activated protein kinase pathways in yeast and plants. Proc Natl Acad Sci USA 95:1938-1943.

Oka A, Sakai H and Iwakoshi S (2002) His-Asp phosphorelay signal transduction in higher plants: Receptors and response regulators for cytokinin signaling in Arabidopsis thaliana. Genes Genet Syst 77:383-391.

Pei ZM, Ghassemian M, Kwak CM, McCourt P and Schroeder JI (1998) Role of farnesyltransferase in ABA regulation of guard cell anion channels and plant water loss. Science 282:287-290.

Perera IY, Hung CY, Brady S, Muday GK and Boss WF (2006) A universal role for inositol 1,4,5-trisphosphate-mediated signaling in plant gravitropism. Plant Physiol 140:746-760.

Pischke MS, Huttlin EL, Hegeman AD and Sussman MR (2006) A transcriptome-based characterization of habituation in plant tissue culture. Plant Physiol 140:1255-1278.

Razem FA, El-Kereamy A, Abrams SR and Hill RD (2006) The RNA-binding protein FCA is an abscisic acid receptor. Nature 439:290-294.

Rojo E, Sharma VK, Kovaleva V, Raikhel NV and Fletcher JC (2002) CLV3 is localized to the extracellular space, where it activates the Arabidopsis CLAVATA stem cell signaling pathway. Plant Cell 14:969-977.

Rolland F, Moore B and Sheen J (2002) Sugar sensing and signaling in plants. Plant Cell 14 Suppl:S185-S205.

Ryan CA, Pearce G, Scheer J and Moura DS (2002) Polypeptide hormones. Plant Cell 14 Suppl:S251-S264.

Smeekens S (2000) Sugar-induced signal transduction in plants. Annu Rev Plant Physiol Plant Mol Biol 51:49-81.

Soyano T, Nishihama R, Morikiyo K, Ishikawa M and Machida Y (2003) NQK1/NtMEK1 is a MAPKK that acts in the NPK1 MAPKKK-mediated MAPK cascade and is required for plant cytokinesis. Genes Dev 17:1055-1067.
Staswick PE, Tiryaki I and Rowe ML (2002) Jasmonate response locus JAR1 and several related Arabidopsis genes encode enzymes of the firefly luciferase superfamily that show activity on jasmonic, salicylic, and indole-3-acetic acids in an assay for adenylation. Plant Cell 14:1405-1415.

Stone JM, Trotochaud AE, Walker JC and Clark SE (1998) Control of meristem development by CLAVATA1 receptor kinase and kinase-associated protein phosphatase interactions. Plant Physiol 117:1217-1225.

Sugden C, Donaghy PG, Halford NG and Hardie DG (1999) Two SNF1-related protein kinases from spinach leaf phosphorylate and inactivate 3-hydroxy-3-methylglutaryl-coenzyme A reductase, nitrate reductase, and sucrose phosphate synthase in vitro. Plant Physiol 120:257-274.

Suzuki T, Miwa K, Ishikawa K, Yamada H, Aiba H and Mizuno T (2001) The Arabidopsis sensor His-kinase, AHk4, can respond to cytokinins. Plant Cell Physiol 42:107-13.

Tavares R, Vidal J, van LA and Kreis M (2002) AtSKtheta, a plant homologue of SGG/GSK-3 marks developing tissues in Arabidopsis thaliana. Plant Mol Biol 50:261-271.

Turner JG, Ellis C and Devoto A (2002) The jasmonate signal pathway. Plant Cell 14:S153-S164.

Wei N and Deng XW (2003) The COP9 signalosome. Annu Rev Cell Dev Biol 19:261-286.

Xiong L, Gong Z, Rock CD, Subramanian S, Guo Y, Xu W, Galbraith D and Zhu JK (2001) Modulation of abscisic acid signal transduction and biosynthesis by an Sm-like protein in Arabidopsis. Dev Cell 1:771-781.

Xiong L, Schumaker KS and Zhu JK (2002) Cell signaling during cold, drought, and salt stress. Plant Cell 14 Suppl:S165S183.

Xu L, Liu F, Lechner E, Genschik P, Crosby WL, Ma H, Peng W, Huang D and Xie D (2002) The SCF(COI1) ubiquitin-ligase complexes are required for jasmonate response in Arabidopsis. Plant Cell 14:1919-1935.

Yang KY, Liu Y and Zhang S (2001) Activation of a mitogenactivated protein kinase pathway is involved in disease resistance in tobacco. Proc Natl Acad Sci USA 98:741-746.

\section{Internet Resources}

CitEST (Citrus ESTs database), http://biotecnologia. centrodecitricultura.br (June 25, 2006).

Genbank, http://www.ncbi.nlm.nih.gov/ (November 6, 2006). Associate Editor: Raquel Luciana Boscariol-Camargo 